\title{
Fluorescence and Photochemical Investigations of Phytochrome in Higher Plants
}

\author{
Vitaly A. Sineshchekov \\ Physico-Chemical Biology, Biology Faculty, M. V. Lomonosov Moscow State University, Moscow 119992, Russia \\ Correspondence should be addressed to Vitaly A. Sineshchekov, vsineshchekov@yahoo.com
}

Received 22 April 2010; Accepted 2 August 2010

Academic Editor: Naohiro Kato

Copyright (C) 2010 Vitaly A. Sineshchekov. This is an open access article distributed under the Creative Commons Attribution License, which permits unrestricted use, distribution, and reproduction in any medium, provided the original work is properly cited.

\begin{abstract}
In higher plants, photoreceptor phytochrome (phy)—photoisomerizing biliprotein working as a light-driven molecular switch-is represented by a small family of phytochrome gene products with phyA and phyB as major species. phyA is unique among other phytochromes mediating photoresponse modes specific only for this pigment (far-red light induced) and also photoresponses characteristic of phyB and other minor phys (red light induced). In our group, in vivo fluorescence investigations of phytochrome were initiated and two native phyA pools—-posttranslationally modified PHYA gene products designated phyA' and phyA" —-were detected in dicots and monocots. They differ by spectroscopic and photochemical parameters, by abundance and distribution in etiolated plant tissues, by light stability, and other phenomenological characteristics, and, most importantly, by their functional properties. This may explain, at least partially, the nature of the uniqueness of the phyA action. In this paper, the data on the phyA polymorphism are summarized with attention to the applied experimental approach.
\end{abstract}

\section{Introduction}

Half a century ago, Butler and coworkers [1] have discovered, using in vivo difference absorption spectroscopy, the key plant photoreceptor phytochrome. This discovery has initiated intensive work along two major lines-(1) physicochemical investigation of the pigment and (2) exploration of its complex functions. The pigment was characterized as a water-soluble homodimer whose monomers have a molecular mass of approx. $125 \mathrm{kDa}$ and comprise 1200 amino acid residues. Each of the apoproteins is covalently associated, via a thioether bond and a cystein residue, with an open tetrapyrrole phytochromobilin (РФB) and contains two major functional domains-chromophore-bearing $\mathrm{N}$ terminal (input) and signaling C-terminal (output). The action of the photoreceptor is based on the initial red-light (R)-induced cis-trans isomerization of the chromophore driving operation of the cycle of photoconversion of the initial dark-adapted R-absorbing form of the pigment (Pr) into its physiologically active far-red-light (FR) -absorbing form (Pfr). This process is reversed under FR or thermally in the dark [2-4].
Photoactivated Pfr form is transferred from the cytoplasm, where the pigment is synthesized, into the nucleus, where it interacts with transduction chain partners and modifies expression of light-dependent genes [5]. The pigment initiates three major modes (or types) of photoregulation process-(i) R-FR-induced irreversible very low fluence responses (VLFR), (ii) R-induced/FR-reversible "classical" responses (LFR), and (iii) FR-induced high irradience responses (HIR). They include such diverse phenomenological reactions as seed germination, transition from scototo photomorphogenesis (de-etiolation), shade avoidance reaction, floral initiation, resetting of the circadian clock, phototropism, modification of gravitropism, and other reactions [6-9].

In the initial period of the phytochrome research, it was generally accepted that all the modes of the photoreactions are mediated by one molecular type of the pigment. Later on, however, phytochrome heterogeneity was clearly demonstrated. Four independent experimental lines of evidence proved this fact-detection of (i) lightlabile (Type I) and light-stable (Type II) phytochromes [10], (ii) immunologically distinguishable phytochromes $[11,12]$, 


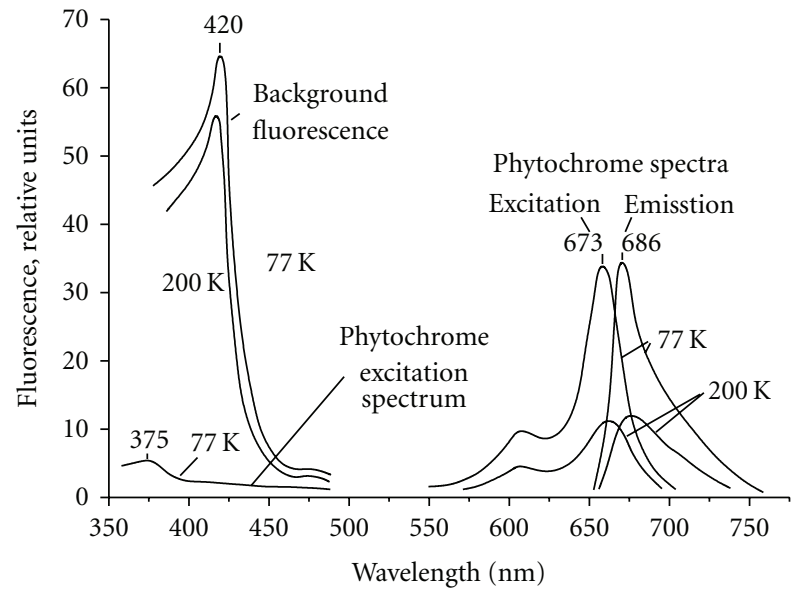

FIgURE 1: Fluorescence of phytochrome in the Pr form in stems of etiolated pea seedlings. Emission spectra were taken under monochromatic excitation at $\lambda_{e}=630 \mathrm{~nm}$, excitation spectra, for emission at $\lambda_{m}=700 \mathrm{~nm}$ at $77 \mathrm{~K}$ and $200 \mathrm{~K}$. Excitation spectrum with the maximum at $375 \mathrm{~nm}$ was calculated in the region 350 $500 \mathrm{~nm}$ with due consideration of green background fluorescence with excitation maximum at $420 \mathrm{~nm}$. Calculation procedure based on different temperature dependence of the excitation bands at 420 and $673 \mathrm{~nm}$, see in [30]. (From [14, 30]).

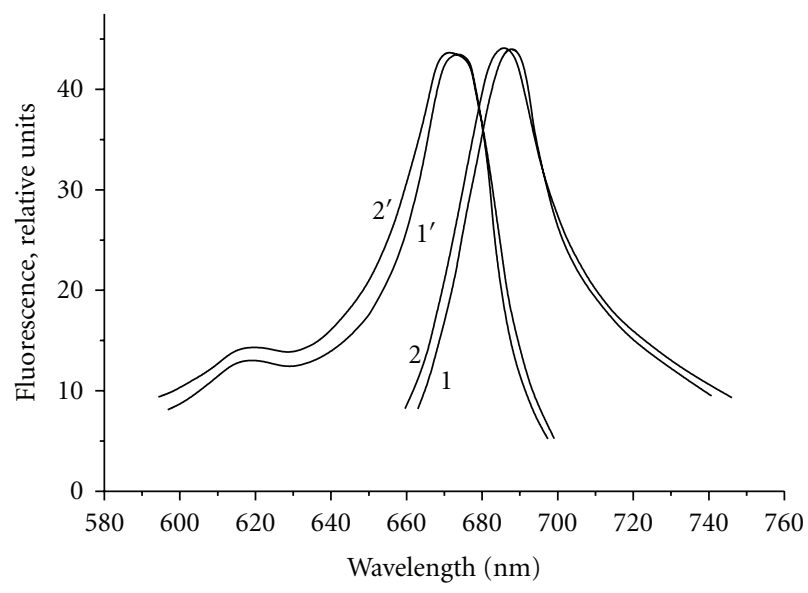

Figure 2: Low-temperature (85 K) emission $\left(1,2, \lambda_{e}=630 \mathrm{~nm}\right)$ and excitation $\left(1^{\prime}, 2^{\prime}, \lambda_{m}=720 \mathrm{~nm}\right)$ fluorescence spectra of the red phytochrome form $\mathrm{Pr}$ in the cells of coleoptiles of etiolated oat seedlings $\left(1,1^{\prime}\right)$ and full-length $124 \mathrm{kDa}$ phytochrome isolated from them $\left(2,2^{\prime}\right)$. (From [36]).

(iii) phytochromes differing by spectroscopic and photochemical properties in vivo [13,14], and, most importantly, (iv) different phytochrome genes and their products $[15,16]$. The major ones are light-labile phytochrome A (phyA) and light-stable phytochrome B (phyB). phyA mediates all the types of the photoresponses-VLFR, HIR, and also LFR [1724]. phyB is capable of mediating only the inductive LFR type. The minor phyC-phyE are functionally close to the major ones or can perform specific functions $[6,23,25]$.
In the case of phyA, there is still a common view that all its complex functions are performed by one and the same molecular type of the pigment. We have shown, however, that there exist two phyA types-posttranslationally modified phyA species with different phenomenological and functional properties. This was done with the use of an original highly sensitive and informative method of low-temperature fluorescence spectroscopy and photochemistry of native phytochrome in the cell (see reviews $[2,26,27]$ ). The aim of this paper is to summarize the obtained data and to promote this relatively simple and efficient experimental approach. I believe that its use, in combination with modern methods of molecular biology, genetics, and photophysiology, may contribute to our deeper understanding of the unique role of phyA in higher plants' photobiology and evolution.

\section{Experimental Approach: \\ Low-Temperature Fluorescence Spectroscopy and Photochemistry of Phytochrome In Vivo}

We have detected phytochrome fluorescence in etiolated plant tissues and based on that developed a highly sensitive technique of in planta phytochrome assay, which proved to be much more sensitive and informative than the classical method of difference absorption spectroscopy $[13,14,28-$ 32]. The fluorescence was characterized at $77-85 \mathrm{~K}$ by (1) the emission/excitation bands at $686 / 673 \mathrm{~nm},(2)$ half-band width of $22-30 \mathrm{~nm},(3)$ high polarization degree $(P \approx 0.4)$, and (4) quantum yield $\varphi_{f}$ of 0.3 dropping down by more than 30-40 fold upon rise of temperature from 77 to $273 \mathrm{~K}$ (Figures 1-3) (for a review of the literature on phytochrome fluorescence and photochemistry in vitro and in vivo, see [2]).

The fact that the emission belonged to phytochrome in its Pr form was shown by the following lines of evidence: (i) its excitation spectrum (Figure 1) was very close to the low-temperature absorption spectrum of phytochrome in vitro (not shown); (ii) there was close similarity between the detected fluorescence of phytochrome and that of phytochrome in vitro (Figure 2) (procedure of in vivo phytochrome emission spectra measurements and correction for background emission of the sample is illustrated by Figure 3 ); (iii) light-induced fluorescence intensity changes were connected with the photoconversions of Pr into Pfr at ambient temperatures, and into the first photoproduct lumi$\mathrm{R}$ stable at low temperatures and they were photoreversible (Figures 3 and 4); (iv) there was a correlation between fluorescence and the content of phytochrome in plant tissues of wild-type plants and phytochrome mutants evaluated with the use of difference absorption spectroscopy; (v) there was no correlation of fluorescence and (proto)chlorophyll(ide) content in tissues as revealed by the use of a chlorophyllless mutant. Fluorescence of lumi-R in situ was also detected with the quantum yield similar to that of $\operatorname{Pr}$ and the emission/excitation bands at $704 \mathrm{~nm}$ and $686 \mathrm{~nm}$. Phytochrome in the Pfr form did not fluoresce even at liquid helium temperatures $(1.5-4 \mathrm{~K}), \varphi_{f}<10^{-4}$. 


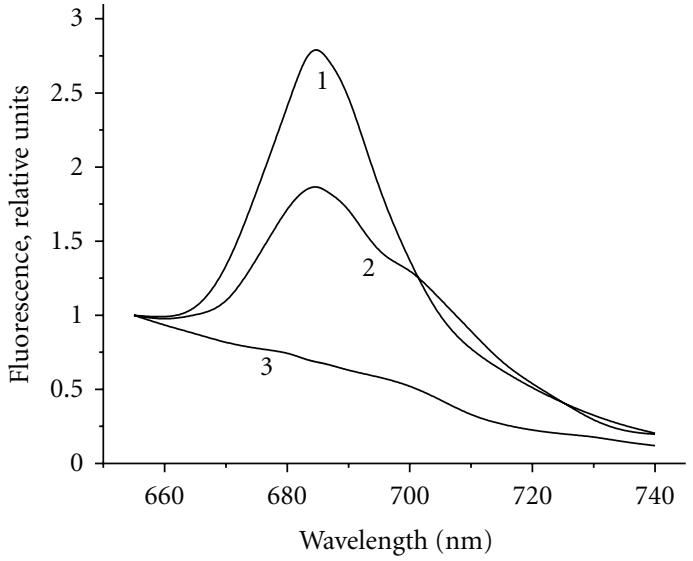

(a)

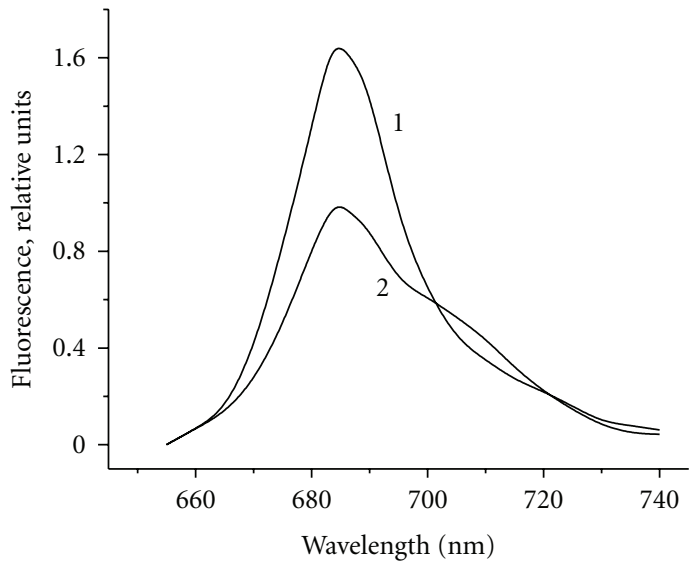

(c)

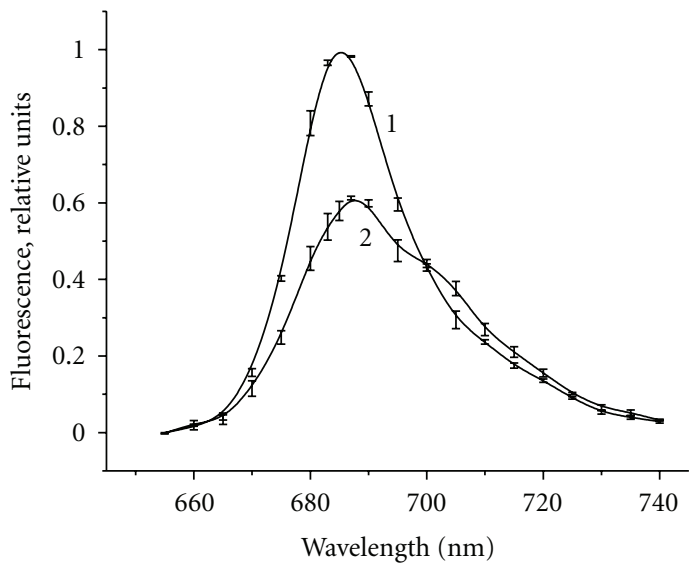

(e)

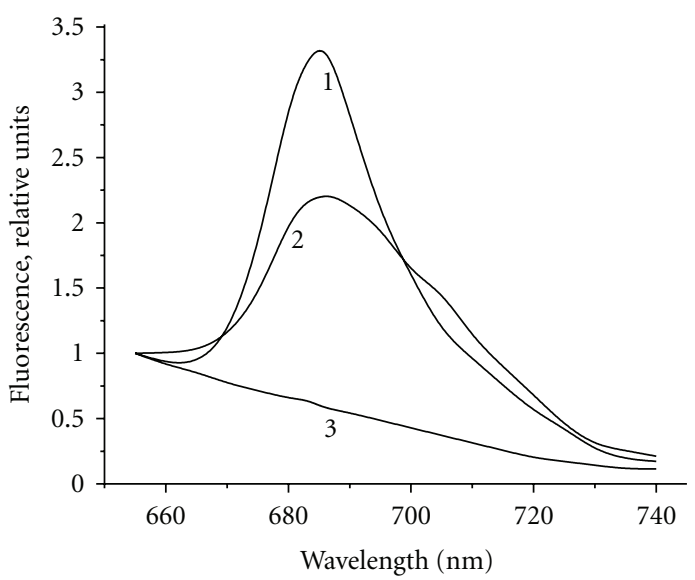

(b)

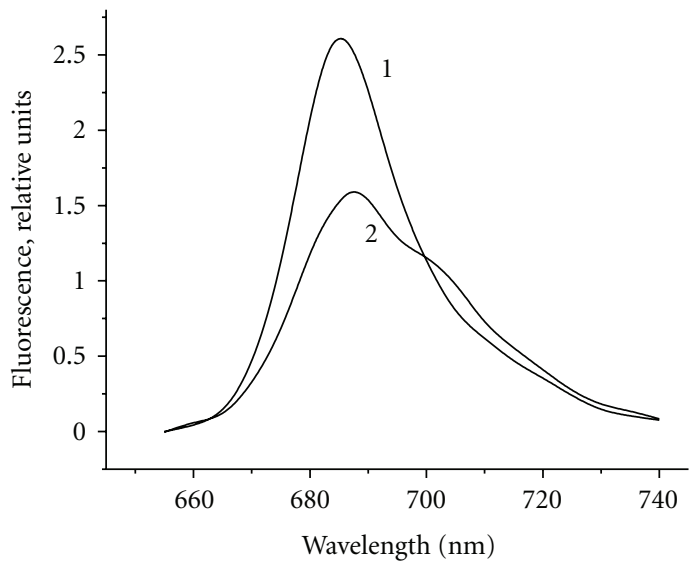

(d)

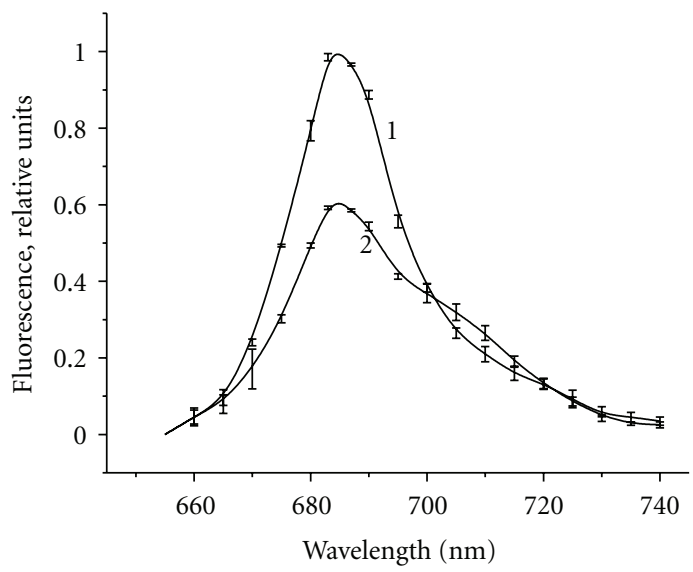

(f)

Figure 3: Raw (a, b), difference (c, d), and normalized (e, f) low-temperature $(85 \mathrm{~K})$ fluorescence emission spectra $\left(\lambda_{e}=632.8 \mathrm{~nm}\right)$ of phytochrome in the tips of rice coleoptiles: in the initial etiolated state, when all the pigment is in its $\operatorname{Pr}$ form (curve 1), and after saturating red $\left(\lambda_{\mathrm{a}}=632.8 \mathrm{~nm}\right)$ illumination at $85 \mathrm{~K}$ converting part of Pr into the first photoproduct lumi-R stable at low temperature $(\operatorname{Pr} \leftrightarrow$ lumi-R photoequilibrium) (curve 2); wild type (a, c, e); phyB mutant (b, d, f). The spectra of etiolated coleoptiles of the rice phyA and phyAphyB mutants (curve 3) are also given in (a) and (b), respectively. The spectra in (c) and (d) belonging to phyA are obtained by subtraction of curve 3 from curves 1 and 2 in (a) and (b), respectively, after their normalization at $660 \mathrm{~nm}$ to 1 , where the emission of phytochrome is negligible. The spectra in (e, f) are the average phyA spectra obtained as in (c, d) of 3-6 different samples after their normalization in the maximum to 1 . The spectra were not corrected for the spectral sensitivity of the fluorimeter. Bars = SD. (From [22]). 


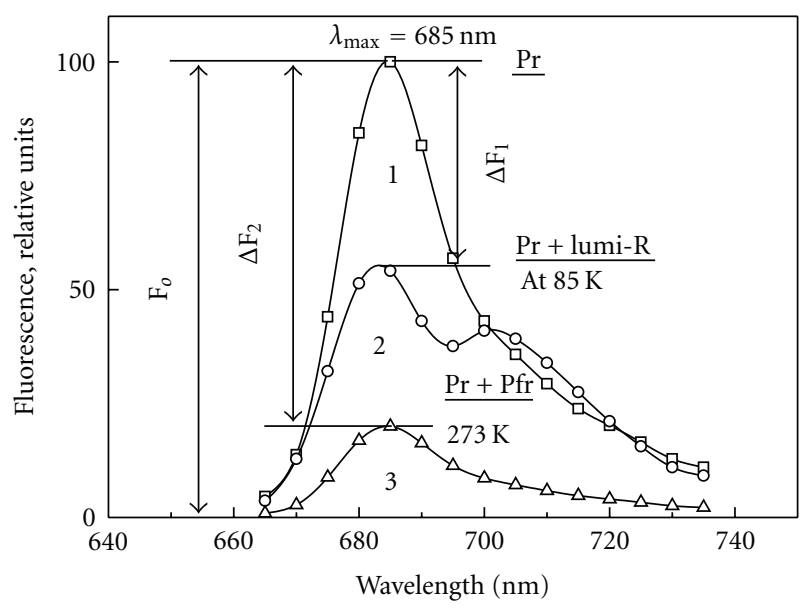

FIgURE 4: The low-temperature fluorescence method of phytochrome in situ assay. To characterize the pigment, three fluorescence spectra (corrected for background emission of the sample) of phytochrome were measured at $85 \mathrm{~K}: 1$ in etiolated tissues (of wheat in this figure) when all phytochrome is in its Pr form, 2 in the same sample after saturating red illumination at $85 \mathrm{~K}$ partially converting Pr into lumi-R, the first stable photoproduct, and 3 in the same sample after thawing at $273 \mathrm{~K}$, saturating red illumination converting Pr into Pfr, and freezing again at $85 \mathrm{~K}$. Four major parameters were obtained from these spectra: position of the emission spectrum $\left(\lambda_{\max }\right)$, total phytochrome content proportional to the fluorescence intensity $\left(\left[\mathrm{P}_{\text {tot }}\right] \approx \mathrm{F}_{0}\right)$, extent of the $\operatorname{Pr} \rightarrow$ lumi-R photoconversion, equal to the relative fluorescence decline $\left(\gamma_{1}=\right.$ $\left.\Delta \mathrm{F}_{1} / \mathrm{F}_{0}\right)$ and characterizing the initial photoreaction, and the extent of the $\operatorname{Pr} \rightarrow \operatorname{Pfr}$ photoconversion $\left(\gamma_{2}=\Delta \mathrm{F}_{2} / \mathrm{F}_{0}\right)$, characterizing the whole phytochrome cycle. (From [26]).

Phytochrome in the Pr form was described in planta by the following parameters: (i) position and shape of emission/excitation (absorption) spectra; (ii) fluorescence quantum yield, $\varphi_{f}$; (iii) $\operatorname{Pr}$ content in relative units, $\left[\mathrm{P}_{\text {tot }}\right]$, proportional to its fluorescence intensity; (iv) extent of the low-temperature $\mathrm{Pr} \rightarrow$ lumi- $\mathrm{R}$ photoconversion to reach a photoequilibrium under $\mathrm{R}, \gamma_{1}$ (measured as variable fluorescence $\left(\Delta \mathrm{F}_{1}\right)$ in the Pr phototransformation and related to its initial fluorescence, $\left.\gamma_{1}=\left(\mathrm{F}_{0}-\mathrm{F}_{1}\right) / \mathrm{F}_{0}=\Delta \mathrm{F}_{1} / \mathrm{F}_{0}\right)$ (Figure 4); (v) extent of the $\mathrm{Pr} \rightarrow \mathrm{Pfr}$ photoconversion carried out at ambient temperatures, $\gamma_{2}$ (measured similarly as variable fluorescence $\left(\Delta \mathrm{F}_{2}\right)$ normalized to the initial Pr fluorescence, $\left.\gamma_{2}=\left(\mathrm{F}_{0}-\mathrm{F}_{2}\right) / \mathrm{F}_{0}=\Delta \mathrm{F}_{2} / \mathrm{F}_{0}\right)$ (Figure 4 ); (vi) activation characterstics of the Pr fluorescence decay determined from temperature dependence of the Pr fluorescence intensity (Figure 5); (vii) activation characteristics of the $\mathrm{Pr} \rightarrow$ lumi$\mathrm{R}$ and reverse lumi- $\mathrm{R} \rightarrow \operatorname{Pr}$ phototransformations based on their temperature dependence (see $[13,14,28-36]$ ).

\section{Photophysical Properties of the Native Phytochrome in the Cell and Its Photoreaction}

The following essential phytochrome characteristics were established based on in planta fluorescence measurements [2,
35]. (1) Singlet excited states of Pr participate in the photoprocesses with the energy of $1.83 \mathrm{eV}$ ( $0-0$ transition). (2) The rule of mirror image symmetry between the absorption and emission spectra of Pr is not strictly followed, which suggests conformational relaxation of the molecule in the excited state. (3) There is an inverse correlation (direct competition) between the Pr fluorescence and its photoreaction. (4) The photoreaction $\mathrm{Pr} \rightarrow$ lumi-R (completed or uncompleted) has an energy barrier $E_{\mathrm{a}}$ in the excited state and is the main (if not the only) temperature-dependent route for the excitation deactivation. (5) There is also a temperature-independent route of deactivation of the Pr excited states. (6) Branching between completed and uncompleted photoreactions takes place at the orthogonal "hot" ground state (prelumi-R). (7) Quantum yield of lumi-R (and eventually of Pfr) formation depends on (i) the yields of prelumi-R formation and (ii) its conversion into lumi-R. (8) The $\mathrm{Pr} \rightarrow$ lumi-R photoreaction is an energy-conserving process. (9) The lumi-R state was characterized by the fluorescence and photochemical properties very similar to those of $\operatorname{Pr}$ with the fluorescence yield approx. equal to that of $\operatorname{Pr}(c a .0 .3$ at $77 \mathrm{~K})$. The energy of the lumi-R singlet excited states participating in its photoprocesses is $1.77 \mathrm{eV}$. Based on these observations and also on the facts that the reaction is a photoisomerization [2-4] and that an intermediate between Pr and lumi-R with excess energy is formed [37], we put forward an energy level scheme of the $\operatorname{Pr} \rightarrow$ lumi-R photoreaction $[2,35]$ (Figure 6).

The yields of fluorescence (transition 3-4 in the scheme), $\varphi_{f}$, and deactivation along the photochemical route (3-5), $\varphi_{p}$, can be expressed as follows:

$$
\begin{gathered}
\varphi_{f}=\frac{k_{f}}{k_{f}+k_{d}+k_{p 0} e^{-E_{a} / R T}}, \\
\varphi_{p}=k_{p 0} \frac{e^{-E a / R T}}{k_{f}+k_{d}+k_{p 0} e^{-E a / R T}},
\end{gathered}
$$

where $k_{f}, k_{d}$, and $k_{p}$ are rate constants of Pr excitation deactivation along the fluorescence, temperature-independent and photochemical routes, respectively (see Figures 5 and 6).

The yield of the $\operatorname{Pr} \rightarrow$ lumi-R phototransformation, $\varphi_{\text {Pr-lumi-R }}$, is equal to the product of the probability $\varphi_{p}$ and of the probability of the Pr reaction to productively terminate, $\varphi_{\mathrm{ab}}$ (route 5-4' from the "hot" ground state of prelumi-R to the ground state of lumi-R)

$$
\varphi_{\text {Pr-lumi-R }}=\varphi_{p} \times \varphi_{\mathrm{ab}},
$$

where $\varphi_{\mathrm{ab}}=k_{\mathrm{ab}} /\left(k_{\mathrm{ab}}+k_{\mathrm{ba}}\right)$, see Figure 6 .

Similar equations should be true for lumi-R and the extent of the $\mathrm{Pr} \rightarrow$ lumi-R phototransformation to reach a photoequilibirum between $\operatorname{Pr}$ and lumi-R $\left(\gamma_{1}\right)$ would depend on the yields of the forward $\operatorname{Pr} \rightarrow$ lumi- $\mathrm{R}$ and reverse photoreactions. These relationships (1-3) may help to understand fluorescence and photochemical behavior of $\operatorname{Pr}$ at different temperatures. At ambient conditions, $\varphi_{p}$ approaches unity since the activation barrier, $E_{\mathrm{a}}$, is easily overcome, and the yield of lumi-R formation $\varphi_{\text {Pr-lumi-R }}$ 


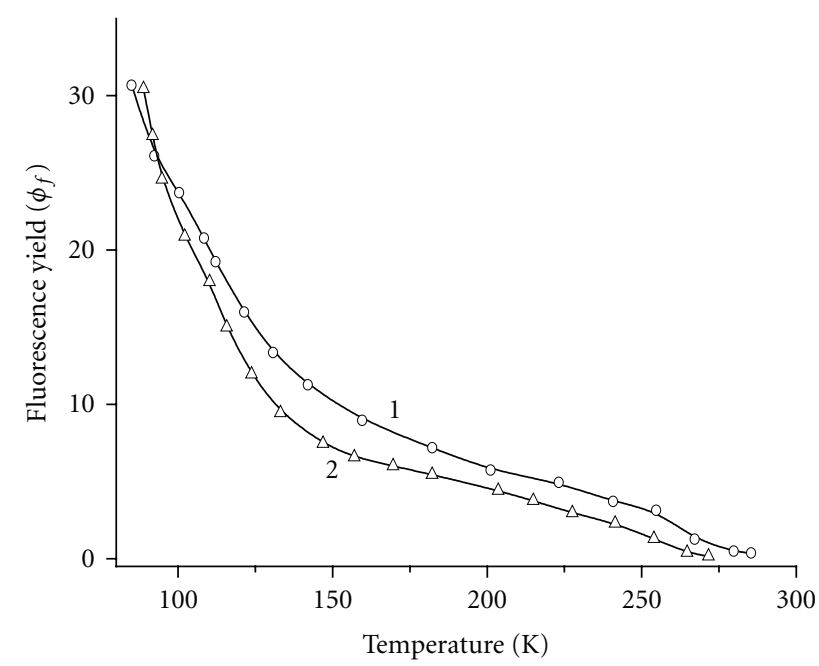

(a)

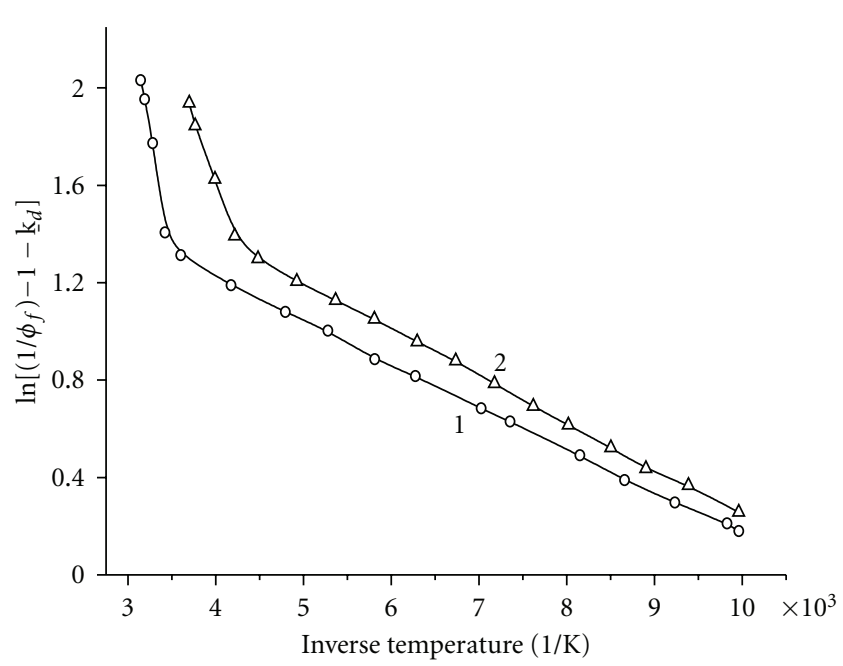

(b)

FIgURE 5: Temperature dependence of the fluorescence quantum yield $\varphi_{f}\left(\lambda_{e}=650 \mathrm{~nm}, \lambda_{m}=686 \mathrm{~nm}\right)$ of the phytochrome Pr form in pea stems (1) and oat coleoptiles (2) of 7-day-old etiolated seedlings: (a) $\varphi_{f}$ versus temperature; (b) $\ln \left[\left(1 / \varphi_{f}\right)-1-\underline{k}_{d}\right]$ versus $1 / \mathrm{T}\left(\underline{k}_{d}=k_{d} / k_{f}\right.$, where $k_{d}$ is the rate constant of the temperature-independent excitation degradation and $k_{f}$ is the radiative rate constant. Quantum yield, $\varphi_{f}$, at $85 \mathrm{~K}$ is equal to 0.25 and $\underline{k}_{d}$ for pea and oat is equal to 2 and 3 , respectively (b, curves 1 and 2). (From [35]).

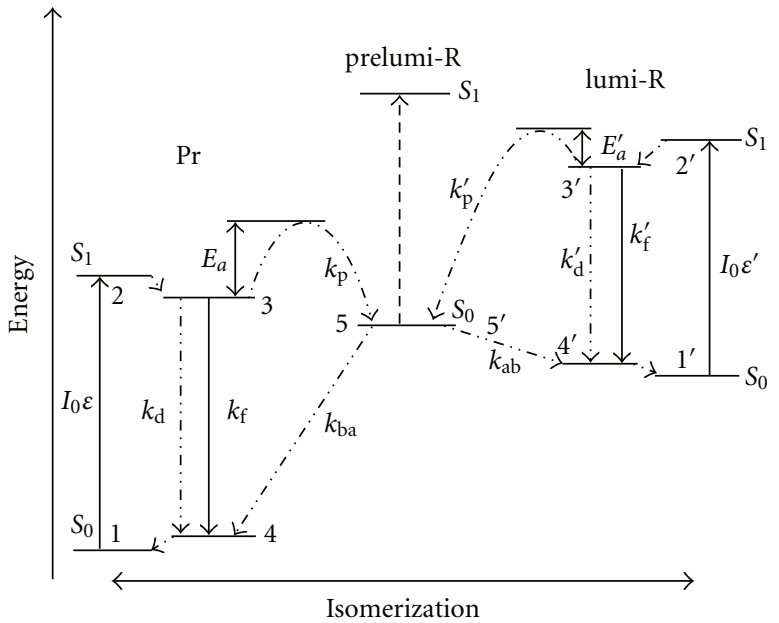

FIGURE 6: The energy level scheme of the photoreaction of the initial red-absorbing phytochrome form (Pr) into the first photoproduct (lumi-R) stable at low temperatures via a shortlived unstable orthogonal intermediate (prelumi-R); $I_{0} \varepsilon, I_{0} \varepsilon^{\prime}-$ absorption coefficients; $k, k^{\prime}$-constants of: fluorescence $\left(k_{f}, k_{f}^{\prime}\right)$, temperature-independent degradation of excitation $\left(k_{d}, k_{d}^{\prime}\right)$, initial photoreaction $\left(k_{p}, k_{p}^{\prime}\right)$, phototransformation into photoproduct $\left(k_{\mathrm{ab}}\right)$, and return into the initial state $\left(k_{\mathrm{ba}}\right) ; E_{\mathrm{a}}$ and $E_{\mathrm{a}}^{\prime}$, activation energy barriers of the direct and reverse photoreactions. The prime sign (') relates to lumi-R. (From [35]).

(and hence of the $\mathrm{Pr} \rightarrow \mathrm{Pfr}$ conversion because lumi-R undergoes thermal relaxation "downhill" to Pfr) should be determined by $\varphi_{\mathrm{ab}}$. At low temperatures, $<150-170 \mathrm{~K}$, where lumi-R is stable, $\varphi_{\text {Pr-lumi-R }}$ would depend primarily on $\varphi_{p}$, since the photoreaction at this temperature is relatively slow and competes with the other deactivation processes (see discussion in [2]).

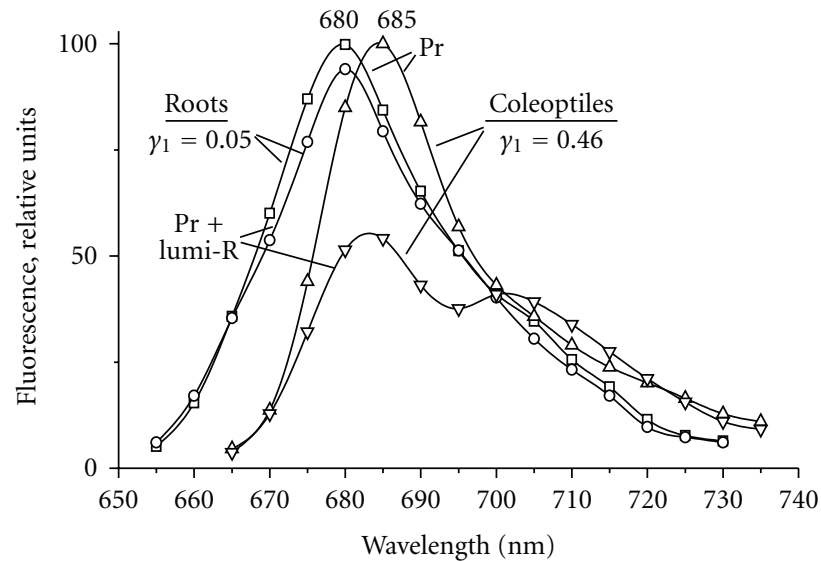

Figure 7: Fluorescence emission spectra $\left(85 \mathrm{~K}, \lambda_{e}=633 \mathrm{~nm}\right)$ of phytochrome in coleoptiles (right) and roots (left) of etiolated wheat taken immediately after darkness, when all the pigment is in the Pr form, and after saturating red $\left(\lambda_{a}=633 \mathrm{~nm}\right)$ illumination at $85 \mathrm{~K}$ partially converting Pr into photoproduct lumi-R stable at low temperatures (photoequilibirum $\mathrm{Pr}+$ lumi-R). Note the differences in the position of the bands and in the extent of the $\operatorname{Pr} \rightarrow$ lumi-R photoconversion, $\gamma_{1}$, in the case of roots and coleoptiles. (From [27]).

\section{Two Spectroscopically and Photochemically Distinct Phytochromes in the Cell}

All the above phytochrome parameters varied depending on different tissues and organs (coleoptiles, stems, and roots) of monocots (oat, wheat, maize, barley, and rice) and dicots (Arabidopsis, pea, potato, tomato, cucumber, cress, bean, and mustard). The most pronounced were changes of the Pr fluorescence temperature dependence, extent of the $\mathrm{Pr} \rightarrow$ lumi-R transformation at low temperature $(0<$ $\left.\gamma_{1}<0.5\right)$ (Figure 7), and activation barrier of the $\operatorname{Pr}$ 


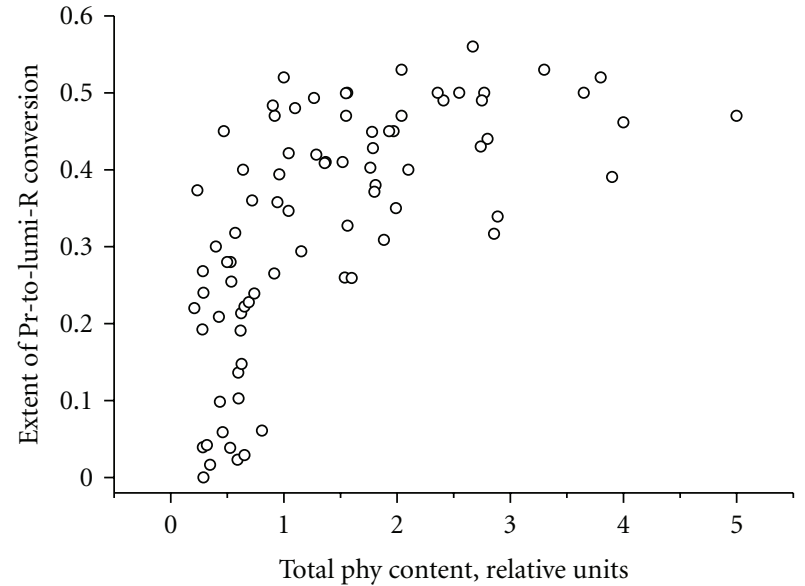

FIGURE 8: Dependence of the extent of the $\mathrm{Pr} \rightarrow$ lumi-R conversion at $85 \mathrm{~K}$ (parameter $\gamma_{1}$ ) on the total phytochrome content in different etiolated wheat seedlings. (From [69]).

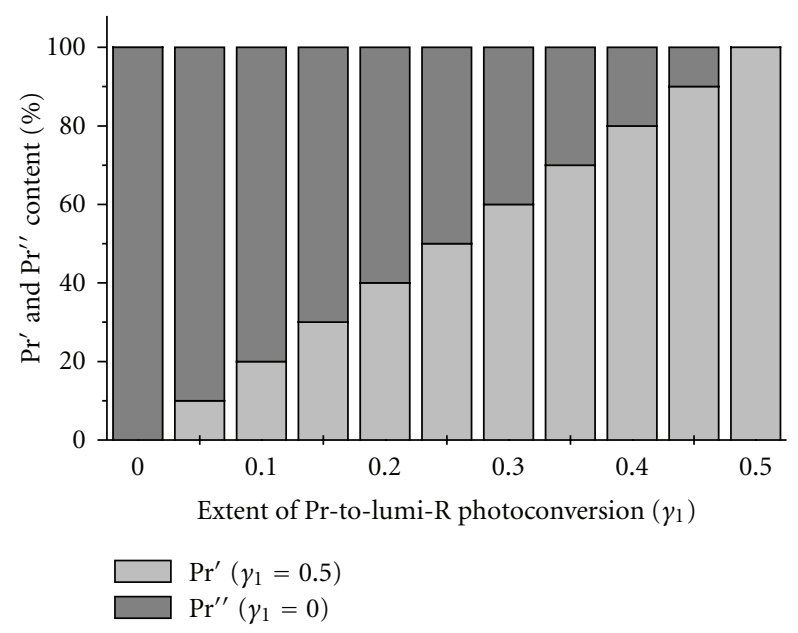

FIgURe 9: Evaluation of the proportion of the $\operatorname{Pr}^{\prime}$ and $\operatorname{Pr}^{\prime \prime}$ types of phytochrome in plant tissues from the individual $\gamma_{1}$ values $(0.5$ and 0 for $\operatorname{Pr}^{\prime}$ and $\operatorname{Pr}^{\prime \prime}$, resp.) and experimental $\gamma_{1}$ values of the sample according to [34]. (From [27]).

photoreaction $\left(\leq 3-4 \mathrm{~kJ} \mathrm{~mol}^{-1}<E_{\mathrm{a}}<c a 35 \mathrm{~kJ} \mathrm{~mol}^{-1}\right)$. Position, $\lambda_{\max }$, of the emission/excitation (absorption) spectra varied from $680-682 / 666-668 \mathrm{~nm}$ to $685-687 / 671-673 \mathrm{~nm}$ (at $85 \mathrm{~K}$ ) (Figure 7 ) and $\gamma_{2}$, from 0.70 to $0.80-0.85$. In general, $\gamma_{1}$ (Figure 8), $\gamma_{2}$ and $\lambda_{\max }$ correlated with $\left[\mathrm{P}_{\text {tot }}\right]$ such that, with the lowering of the latter, a decline in these parameters was also observed.

These variations were explained (in the framework of the above scheme) by the existence of two distinct phenomenological species (designated $\mathrm{Pr}^{\prime}$ and $\mathrm{Pr}^{\prime \prime}$ ) possessing extreme photochemical and spectroscopical values: $\operatorname{Pr}^{\prime}$-longer wavelength $\left(\lambda_{\max }=685-687 / 671-673 \mathrm{~nm}\right)$ with high $\gamma_{1}^{\prime}(0.49 \pm 0.03)$ and relatively low $E_{\mathrm{a}}$ (hundreds $\mathrm{J}$ $\mathrm{mol}^{-1} \leq E_{\mathrm{a}} \leq 3-4 \mathrm{~kJ} \mathrm{~mol}^{-1}$ ) and $\mathrm{Pr}^{\prime \prime}$ - shorter wavelength $\left(\lambda_{\max }=680-682 / 666-668 \mathrm{~nm}\right)$, inactive at low temperature $\left(\gamma_{1}^{\prime \prime} \rightarrow 0\right)$ and with relatively high $E_{\mathrm{a}}$ (it is higher by approx.

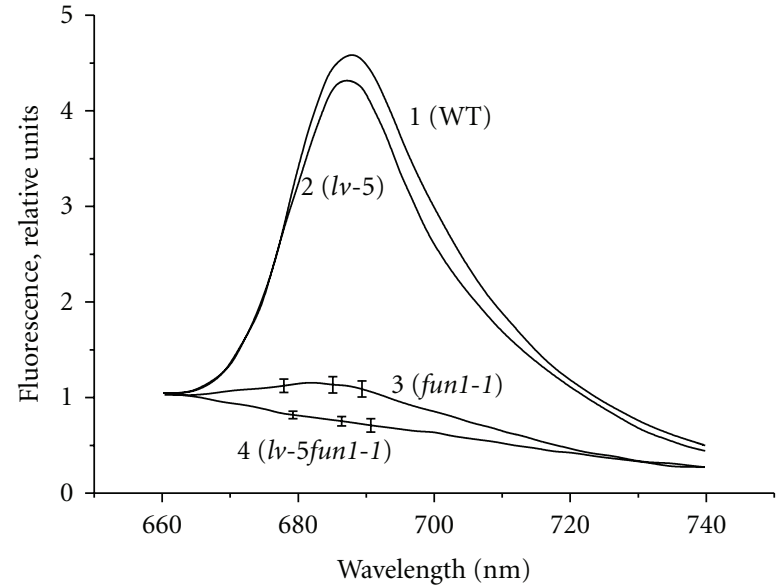

FIGURE 10: Fluorescence emission spectra of phytochrome in the Pr form $\left(85 \mathrm{~K}, \lambda_{e}=633 \mathrm{~nm}\right)$ in etiolated seedlings of phytochromedeficient mutants (not corrected for the background fluorescence and for spectral sensitivity of the spectrofluorimeter): epicotyls of wild-type pea (Pisum sativum L. cv. Torsdag) (1), phyB-deficient (lv-5) mutant (2), phyA-deficient (fun1-1) mutant (3), and the double phyAphyB-deficient (lv-5fun1-1) mutant (4). Spectra (3) and (4) are means of experimental spectra and the bars indicate SE. (From [39]).

a factor of 10 than that of $\left.\operatorname{Pr}^{\prime}\right)$. At ambient temperatures, this barrier is easily overcome in both $\mathrm{Pr}$ species and does not practically affect the extent of the $\mathrm{Pr} \rightarrow \mathrm{Pfr}$ conversion. From the total phytochrome content, $\left[\mathrm{P}_{\text {tot }}\right]$, proportional to its fluorescence intensity and the contrasting $\gamma_{1}^{\prime}$ and $\gamma_{1}^{\prime \prime}$ values for $\operatorname{Pr}^{\prime}$ and $\operatorname{Pr}^{\prime \prime}$, their proportion and content in plant tissues could be easily estimated (Figure 9): the share of $\operatorname{Pr}^{\prime}$ is calculated as the experimental $\gamma_{1}$ parameter divided by the individual $\gamma_{1}^{\prime}$ value of $\operatorname{Pr}^{\prime}\left(\gamma_{1}^{\prime} \approx 0.5\right), \gamma_{1} / \gamma_{1}^{\prime}$, and the shair of $\operatorname{Pr}^{\prime \prime}$, respectively, as $\left[1-\left(\gamma_{1} / \gamma_{1}^{\prime}\right)\right]$ (see procedure in [34]). It was shown that $\operatorname{Pr}^{\prime}$ is the bulk species in growing etiolated tissues, variable by its content and light-labile whereas $\operatorname{Pr}^{\prime \prime}$ is the minor, more evenly distributed in organs and tissues and relatively light-stable (Table 1). The content of $\operatorname{Pr}^{\prime}$ grows almost linearly with $\left[\mathrm{P}_{\text {tot }}\right]$ in sample tissues whereas that of $\mathrm{Pr}^{\prime \prime}$ reaches early saturation (data reviewed in $[2,26,27]$ ).

\section{Two Native Phytochrome A Pools}

In order to find out possible correlation between the observed $\operatorname{Pr}^{\prime}$ and $\operatorname{Pr}^{\prime \prime}$ phenomenological types and the two major phytochromes, phyA and phyB, we turned to phytochrome-deficient mutants and transgenic plants expressing different phytochromes. In the double phyAphyB mutants of Arabidopsis, pea (Figure 10) and rice (Figure 3) practically no phytochrome fluorescence was observed, suggesting that the fluorescence of $\operatorname{Pr}^{\prime}$ and $\mathrm{Pr}^{\prime \prime}$ in the wild types belonged to the two major phytochromes [22, 38 , 39]. Further, practically only $\operatorname{Pr}^{\prime \prime}$ was found in phyA mutants of Arabidopsis and pea (Figure 11(a)), and authentic phyB overexpressed in Arabidopsis and Arabidopsis phyB overexpressed in transgenic potato (Figure 11(b)) was of 


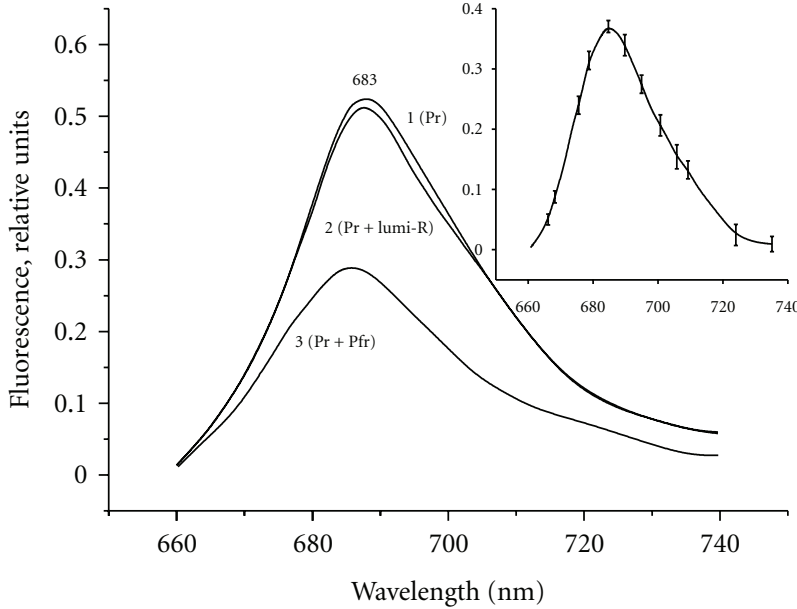

(a)

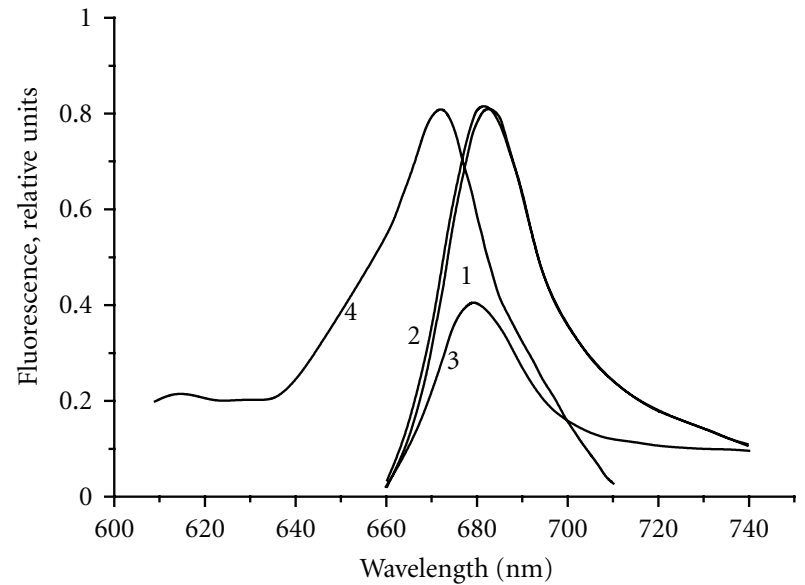

(b)

Figure 11: Low-temperature $\left(85 \mathrm{~K}, \lambda_{e}=633 \mathrm{~nm}\right)$ fluorescence emission spectra of phyB in the Pr form in etiolated epicotyls of phyAdeficient, fun1-1, pea mutant (a) and of Arabidopsis phyB expressed in transgenic potato (DARA12 strain, lower parts of etiolated stems after red-light-induced destruction of phyA, $\left.\lambda_{a}=662 \mathrm{~nm}, 3.5 \mathrm{~h}, 293 \mathrm{~K}\right)(\mathrm{b}):(1)$ in the state when all the pigment is in the Pr form, that is, after darkness or far-red (>720 nm) saturating illumination at $293 \mathrm{~K}$ converting Pfr into Pr; (2) after saturating illumination with actinic red light $(633 \mathrm{~nm}, 85 \mathrm{~K})$ to reach the equilibrium between $\operatorname{Pr}$ and lumi-R, and (3) after thawing the samples at $273 \mathrm{~K}$, illumination with saturating red $(633 \mathrm{~nm})$ light to convert Pr into Pfr and freezing again at $85 \mathrm{~K}$. Insert in (a) is the mean of the experimental spectra of etiolated epicotyls with the bars indicating the standard error. Curve 4 in (b) is the low-temperature excitation spectrum of $\operatorname{Pr}\left(\lambda_{m} \geq 720 \mathrm{~nm}\right)$, corresponding to the emission spectrum 1 . Note the lack of the effect of the red-light actinic illumination on the emission spectrum at $85 \mathrm{~K}$ (no, or low, photochemical Pr conversion into lumi-R, $\left.\gamma_{1} \rightarrow 0\right)$ and relatively low extent of the $\operatorname{Pr} \rightarrow \operatorname{Pfr}$ conversion $\left(\gamma_{2} \leq 0.5\right)$. (From [39, 40]).

TABle 1: Characterisitcs of the two phenomenological phytochrome types, $\operatorname{Pr}^{\prime}$ and $\operatorname{Pr}^{\prime \prime}$, in etiolated dicotyledonous and monocotyledonous plants representing two native phyA types, phyA' and phyA", respectively.

\begin{tabular}{|c|c|c|}
\hline \multirow{2}{*}{ Parameter } & \multicolumn{2}{|c|}{ Phy type } \\
\hline & $\operatorname{Pr}^{\prime}=$ phyA $^{\prime}$ & $\operatorname{Pr}^{\prime \prime}=$ phyA $^{\prime \prime}(+ \text { phyB })^{*}$ \\
\hline Position of spectra, $\lambda_{\max }$ & Longer-wavelength $(685 / 672 \mathrm{~nm})$ & Shorter-wavelength $(680 / 667 \mathrm{~nm})$ \\
\hline Half-band width, $\Delta \lambda$ & $22-24 \mathrm{~nm}$ & $30 \mathrm{~nm}$ \\
\hline $\operatorname{Pr} \rightarrow$ lumi-R conversion, $85 \mathrm{~K}, \gamma_{1}$ & $0.49 \pm 0.03$ & $\leq 0.05$ \\
\hline Activation energy, $E_{\mathrm{a}}$ & $\leq 1 \mathrm{~kJ} \mathrm{~mol}^{-1}$ & $\geq 10 \mathrm{~kJ} \mathrm{~mol}^{-1}$ \\
\hline $\operatorname{Pr} \rightarrow \operatorname{Pfr}$ conversion, $\geq 273 \mathrm{~K}, \gamma_{2}$ & $0.80-0.85$ & 0.75 \\
\hline Content in tissues & Major, variable & Minor, conserved, saturable \\
\hline Light lability & Light-labile & Relatively light-stable \\
\hline
\end{tabular}

* phyB also belongs to the $\operatorname{Pr}^{\prime \prime}$ type.

the $\operatorname{Pr}^{\prime \prime}$ type. This proves that phyB belongs to the $\operatorname{Pr}^{\prime \prime}$ phenomenological pool (Table 1) $[38,40]$.

On the contrary, in phyB mutants of cucumber [41], Arabidopsis [38], pea [39], and rice [22] both $\operatorname{Pr}^{\prime}$ and $\operatorname{Pr}^{\prime \prime}$ were observed (Figures 3 and 10) and their content was almost identical to that in the wild type (WT) (Figure 12). Besides, oat phyA overexpressed in Arabidopsis, tobacco and wheat, and also authentic phyA overexpressed under strong promoter in transgenic potato were found to produce both $\operatorname{Pr}^{\prime}$ and $\operatorname{Pr}^{\prime \prime}[38,42,43]$. This strongly implies that there are two phenomenological pools of phyA with the properties of $\operatorname{Pr}^{\prime}$ and $\operatorname{Pr}^{\prime \prime}$ - phyA $^{\prime}$ and phyA ${ }^{\prime \prime}$, respectively. The absolute and relative content of phyA' and phyA $^{\prime \prime}$ depended on plant species and tissues, on the stage of plant development, illumination conditions, and other physiological factors thus revealing deep distinctions of their phenomenological properties (Table 1).

\section{To the Nature of the Two Phytochrome A Pools}

Both phyA species are full-length phytochromes, the products of one and the same gene, and phyA for its differentiation undergoes plant-specific posttranslational modification. This is suggested by the following facts. Recombinant Arabidopsis and Oryza phyA expressed in yeast cells (Saccharomyces cerevisiae) and Arabidopsis phyA expressed in Pichia pastoris and in E. coli, which was reconstituted with phycocyanobilin, $\mathrm{PCB}$, or phytochromobilin, $\mathrm{P} Ф \mathrm{~B}$, in situ, is 


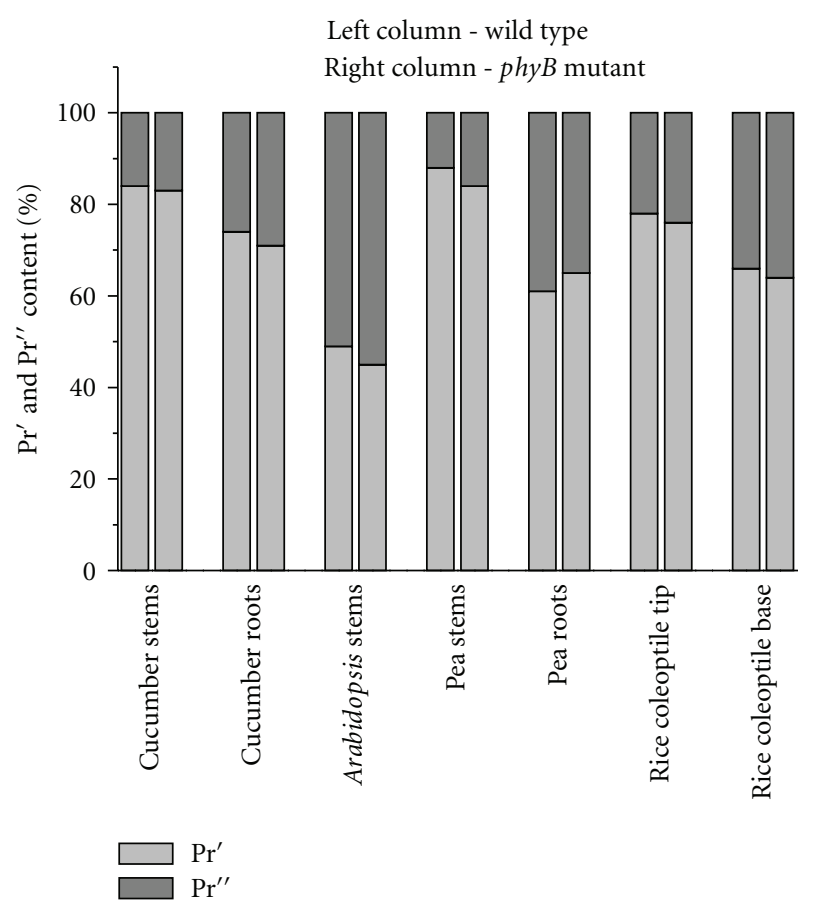

FIgURE 12: Relative content of the two phytochrome phenomenological types, $\operatorname{Pr}^{\prime}$ and $\operatorname{Pr}^{\prime \prime}$, in etiolated dicotyledonous and monocotyledonous plants and their phyB-deficient mutants. Close similarity in the content of $\operatorname{Pr}^{\prime}$ and $\operatorname{Pr}^{\prime \prime}$ between the wild-type plants and the mutants strongly suggest that there exist two phyA species, phyA ${ }^{\prime}$ and phyA", with the properties of $\operatorname{Pr}^{\prime}$ and $\operatorname{Pr}^{\prime \prime}$, respectively. (From [27]).

represented only by the phyA" type $[44,45]$. Secondly, the site for the phy $\mathrm{A}^{\prime}$ and phyA" differentiation is restricted to the small region near the $\mathrm{N}$-terminus ( $\mathrm{N}$-terminal extension, NTE) as suggested by experiments on truncated phyA overexpressors: the 7-69 amino acid residues stretch was found to be critical for the phyA' formation whereas the 6-12 stretch, for phyA" $[43,46]$. In other words, the $\Delta 7-69$ phyA was represtented by phyA" whereas $\Delta 6-12$ phyA, by phyA'.

The presumed posttranslational modification of phyA and its differentiation into phy $\mathrm{A}^{\prime}$ and $\mathrm{phyA}^{\prime \prime}$ may include its phosphorylation. phyA is known to be a phosphoprotein in the Pr form autophosphorylated at Ser8 and Ser18 in the 65 amino acid N-terminal extension [47-51]. In our experiments, dephosphorylation of native (oat) phyA in vitro with the use of animal phosphatase caused lowering of [phyA $\mathrm{p}^{\prime}$ and concomitant rise of [phyA $\left.{ }^{\prime \prime}\right]$ with an approx. 2.5-fold decline of the phyA'/phyA" ratio suggesting that phyA' and phyA" are, respectively, phosphorylated and dephosphorylated species [2]. Indirect support to this notion is that around 95\% phyA in etiolated oats is phosphorylated [52] and that in our experiments phyA' reached this proportion [34]. It is of interest in this connection that interaction of phyA with substrates of its kinase activity affects relative phyA'/phyA" content. The lack of PKS1 and PKS2 (Phytochrome Kinase Substrates $[48,53,54]$ ) in the case of the double pks1pks2 mutant of Arabidopsis brought about a shift of the ratio towards phyA" suggesting that these proteins favor formation of phyA' [55]. There was no effect, however, in the case of the single $p k s 1$ and $p k s 2$ mutants, which indicates redundancy between PKS1 and PKS2 in this regard. The equilibrium between phyA ${ }^{\prime}$ and phyA" was also shown [26] to depend on the interaction of phyA with the blue photoreceptor cryptochrome 1, cryl [56], whose activity is known to be enhanced by phytochromeinduced phosphorylation [57]. In the Arabidopsis mutant hy4 lacking cryl, we observed a shift of the phyA'/phyA" equilibrium towards phy $\mathrm{A}^{\prime}$, suggesting that phyA-cryl interaction favors, in contrast to PKS1 and PKS2, formation of phyA ${ }^{\prime \prime}$. Interpretation of these data is difficult at present. However, it is clear that these proteins may have relation to the phyA species formation and phosphorylation of phyA or its partner proteins can be considered as a likely source of structural distinctions between phyA $\mathrm{A}^{\prime}$ and phyA".

Finally, the two phyA species may differ by its membrane (protein) association in the cell. Amphiphilic phytochrome sequences in the PHYA apoprotein makes it potentially capable of interaction with other cellular macromolecules [58], and biochemical experiments have detected a minor membrane-associated fraction of phyA (see $[59,60]$ and the literature cited therein). Physical interactions of phyA with other partner proteins and complex formation are also well documented [48, 49, 53, 61]. Our experiments [62] revealed that soluble and membrane-associated phytochrome fractions extracted from etiolated maize coleoptiles were enriched by $\mathrm{phyA}^{\prime}$ and $\mathrm{phyA}^{\prime \prime}$, respectively, pointing to phy $\mathrm{A}^{\prime \prime}$ association with membrane (proteins) as a possible nature of their differences. It should be also noted that the content of phyA" decreased in the order maize, pea, and oats as did the content of membrane-associated phyA in these species providing additional support for the above hypothesis. Interestingly, soluble phyA $\mathrm{A}^{\prime}$ can be transformed into presumably more hydrophobic phyA" upon extreme dehydration of plant tissues suggesting a role of water in stabilizing the phyA' conformation [63].

\section{Functional Distinctions between PhyA' $^{\prime}$ and PhyA ${ }^{\prime \prime}$}

Phenomenological differences between the phyA types strongly imply their possible functional distinctions. Taking into account that the key event in the mechanism of phytochrome functioning is its light-induced transfer from the cytoplasm to the nucleus [64] and probable association of phyA" with membrane (protein) (see above), one may expect diversity in their intracellular localization and in the process of the nuclear-cytoplasmic partitioning. Earlier, it was shown that phyA fused to green fluorescent protein (chimerical phyA-GFP) translocates from cytoplasm to the nucleus within several minutes after far-red illumination forming there speckles of different types [65]. We have found that Arabidopsis phyA-GFP expressed in phyA-deficient Arabidopsis and rice phyA-GFP overexpressed in transgenic tobacco are spectroscopically and photochemically close to the native phyA and that they are represented by both 
phyA types-phyA'-GFP and phyA" -GFP. This suggests that interaction of phyA with GFP does not affect the properties and relative content of the two phyA forms and that both of them may be potential participants of the light-induced nuclear translocation [66].

Further, mutant Arabidopsis phyA truncated at the amino acid stretch 6-12 ( $\triangle 6-12$ phyA-GFP) is almost entirely represented by phyA' (by more than $80 \%$ ) whereas full-length (FL) phyA-GFP contained both phyA species in comparable amounts (53\% phyA' and $47 \%$ phyA $^{\prime \prime}$ ) characteristic of the wild-type Arabidopsis [67]. This observation implies that the differences in the nuclear translocation of FL phyA-GFP and $\Delta 6-12$ phyA-GFP [68], namely, formation of both (i) nuclei with many tiny spots and (ii) nuclei with few small spots in the case of FL phyA-GFP and of only the first type of the nuclei in the case of $\Delta 6-12$ phyA-GFP, may be connected with the differences in the content of the phyA pools in them. Thus, we may conclude that phyA' participates in the nuclear translocation and hypothesise that the two patterns of speckle formation could be associated with phyA' and phyA", respectively.

Photophysiological differences between the two phyA pools were revealed in experiments on correlation between the phenotype of phyA over- and underexpressors and alterations in the content of phyA pools in them. Transgenic potato overexpressing endogenous phyA had a more pronounced FR-HIR, whereas underexpressors, a delayed FR-HIR. At the same time, most dramatic variations were observed in the concentration of phyA $^{\prime}$, suggesting that the changes in the phenotype are primarily connected with this pool and to a lesser extent with the minor phyA" [42]. Also, transgenic wheat overexpressing oat phyA had an excess of primarily phyA' in the dark and under FR. Since this transgenic wheat acquired high irradience responses under FR (FR-HIR) for growth inhibition, leaf unrolling, and antocyanin formation, which were not characteristic of the wild-type plants, one may conclude that phyA $^{\prime}$ is responsible for FR-HIR [69].

Experiments with truncated phyA unable to form phyA' or phyA" provided another opportunity to look into the functional roles of the two phyA pools. Oat phyA lacking the $6-\mathrm{kDa} \mathrm{N}$-terminal domain overexpressed in transgenic tobacco (NA line with $\Delta 7-69$ phyA) failed to form phyA (phyA" overexpressor), while the full-length oat (FL) phyA species produced both phyA' and phyA" (phyA'+phyA" overexpressor) [43]. Thus, distinctions of the NA phenotype from that of wild type (WT) and FL could be associated with phyA". As a measure of the phenotype alterations, we followed changes in (1) the content of inactive and active protochlorophyllide, Pchlide ${ }^{633}$ and Pchlide ${ }^{655}$, and (2) in growth responses upon FRc- or Rc-illumination. FRc brought about an increase of both Pchlides in all the transgenic lines (Figure 13). However, in NA the effect was considerably lower than in WT while it was the highest in FL suggesting that phyA" was not active and interfered with the endogenous phyA responses in seedlings grown under FR [70]. The shape and length of the NA plants were the same under FRc as in darkness in contrast to WT and FL. However, under $\operatorname{Rc}(\lambda \geq 660 \mathrm{~nm})$, NA revealed a higher effect
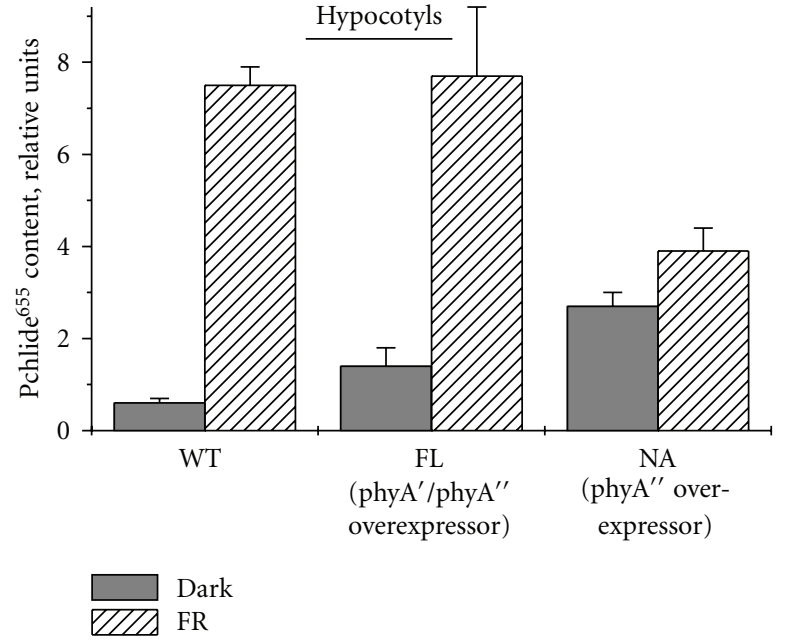

FIGURE 13: phyA" is inactive under far-red light and inhibits phyA' action. This is revealed by induction of Pchlide ${ }^{655}$ biosynthesis in hypocotyls of transgenic tobacco overexpressing full-length oat phyA (FL, represented by both phyA species) and $\Delta 7-69$ deleted phyA (NA, consisting of only phyA"). The seedlings were grown in darkness (left column) and in far-red $\left(\lambda_{a} \geq 720 \mathrm{~nm}, \mathrm{I}=0.1 \mathrm{~W} \mathrm{~m}^{-2}\right)$ light (right column). (From [70]).

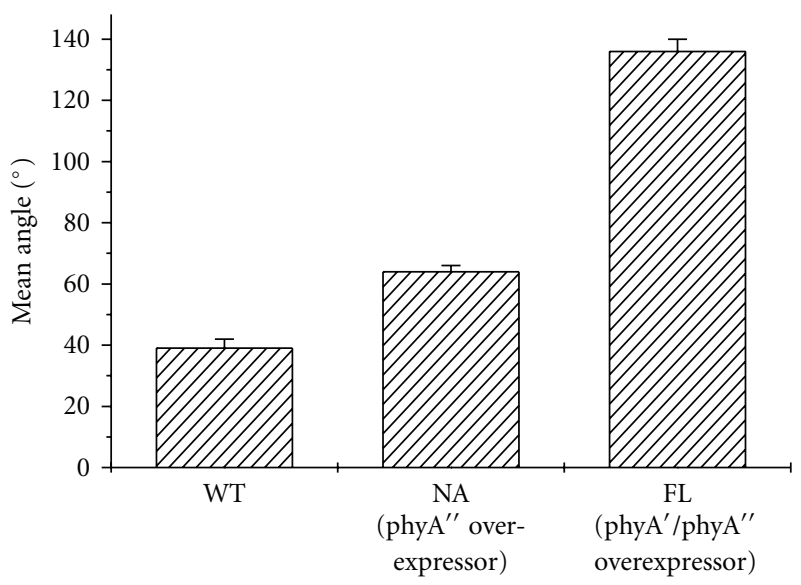

FIGURE 14: phyA" can participate in red-light (R)-induced responses characteristic of phyB: in the case of cotyledon unfolding Rc had more profound effects on the phyA" tobacco overexpressor (NA) than on WT, although not as high as on the overexpressor of both phyA' and phyA" (FL). Seedlings were grown under constant red illumination $\left(\lambda_{a}=660 \mathrm{~nm}, \mathrm{I}=0.1 \mathrm{~W} \mathrm{~m}^{-2}\right)$ at $293 \mathrm{~K}$. (From [71]).

of cotyledon unfolding than WT [71] (Figure 14). Thus, phyA activity under FRc $(\lambda \geq 720 \mathrm{~nm})$ could be associated with phy $\mathrm{A}^{\prime}$ whereas phy $\mathrm{A}^{\prime \prime}$ is inactive and even suppresses the action of endogenous phy $\mathrm{A}^{\prime}$. At the same time, it may function under Rc. Interestingly, overexpressed phyB behaves similarly to phy $\mathrm{A}^{\prime \prime}$ causing dominant negative interference on phyA-mediated inhibition of hypocotyl growth under FRc [72]. The effect of phyA" overexpression was observed even 


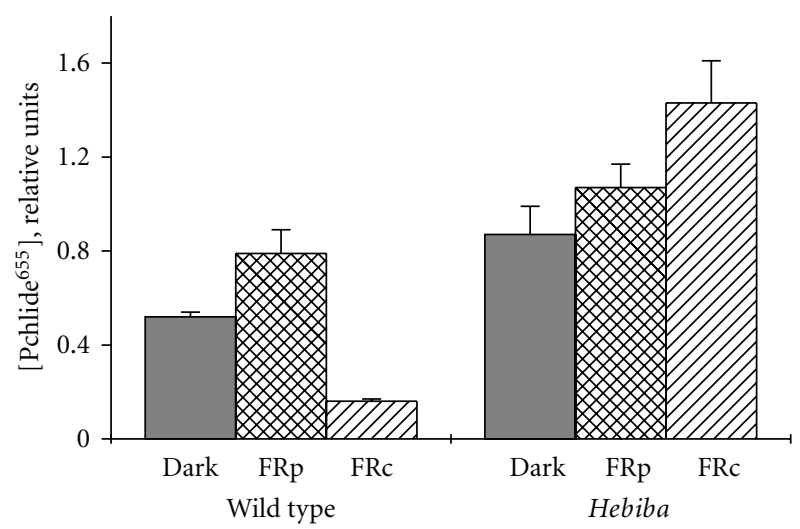

FIGURE 15: Content of the active protochlorophyllide $\left(\right.$ Pchlide $\left.^{655}\right)$ in coleoptiles of wild-type rice and its mutant hebiba deficient in the hormone jasmonic acid grown in darkness and under pulsed (FRp) and constant (FRc) far-red light of equal fluence. Note the opposite effects of FRp and FRc in wild type and of FRc in wild type and hebiba. (From [84]).

in the dark: the level of the active Pchlide ${ }^{655}$ and inactive Pchlide ${ }^{633}$ in stems was much higher in the NA tobacco line overexpressing phyA" than in WT (Figure 13). It should be noted that phyB was also shown to have some activity in the absence of red-light activation [73]. Finally, phyA" may also play a role in the circadian clock regulation under red light. This is suggested by the observations that the crylmutation in Arabidopsis causes a decline in the phyA" content and a concomitant increase of that of phyA' [26] (see above) and, at the same time, impairment in phyA input to the circadian clock under low fluence rate red light [74].

There are indications that phyA' may be active in VLFR as well. This is implied by the observations that Arabidopsis $\Delta 6-12$ phyA is represented primarily by the phyA' species (see above) and that Arabidopsis expressing this truncated phyA has either exaggerated [68] or normal [75] VLFR and reduced HIR. On the other hand, point-mutated phyA302 with Glu777 changed to Lys [76] and phyA-303 with R384K substitution [77] both defective in HIR but with normal VLFR had the same or somewhat higher ratio of the phyA'/phyA" pools than that in the wild type [78]. This can be interpreted as that the impairment in HIR of the two mutant phyA species is not connected with the disappearance or decline of phyA' and suggests, together with the other data (see above), that phyA' is likely to mediate both HIR and VLFR.

Among the FR-HIR reactions of particular importance is obviously regulation by phyA of protochlorphyllide oxido reductase (POR) and active Pchlide ${ }^{655}$ accumulation which was found to be negative [79-82]. However, we have shown that it is not a universal phenomenon-the sign and magnitude of the FRc effect on Pchlide ${ }^{655}$ accumulation depend on plant species and, within the plant, on the organ or the tissue used [22, 70]. In cotyledons of tomato and Arabidopsis, and in rice coleoptiles, a decline of the Pchlide ${ }^{655}$ production was observed in line with the data in the literature [81,
83]. Quite on the contrary, in cotyledons of tobacco and leaves of pea, and also in upper stems of tobacco, pea, tomato, and Arabidopsis, a positive effect of FRc on Pchlide ${ }^{655}$ content of different magnitude was detected. Interestingly, the effects on protochlorophyllide biosynthesis (and also growth responses) were more pronounced in $p h y B$ rice mutant than in wild-type rice [22], supporting the notion that phyB may interfere with the action of phyA ${ }^{\prime}$ (see above). The phenomenon of the reversion of the sign of the FRc effects on Pchlide ${ }^{655}$ was also detected on rice hebiba mutant deficient in the hormone jasmonic acid [84]. In the wild type, FRc was inhibiting whereas in the mutant it stimulated the synthesis of Pchlide ${ }^{655}$ (Figure 15). The negative effect is not connected with the availability of the chromophore, because the free chromophore, Pchlide ${ }^{633}$, experienced an increase under FRc. Also, feeding of etiolated seedlings with the Pchlide precursor, $\delta$-aminolevulinic acid, increased the Pchlide ${ }^{633}$ content by $10-100$-fold while the content of Pchlide ${ }^{655}$ remained practically unchanged [85], suggesting that the limiting factor for the Pchlide ${ }^{655}$ formation is the apoprotein.

The fact that the sign and magnitude of the effect of FRc on Pchlide ${ }^{655}$ accumulation change depending on the tissue (or organ) used resembles the effect of the light regulation of PHYA gene [86], which together with the POR gene belongs to the small group of FRc-downregulated genes. The authors have found three PHYA transcripts that were differentially regulated by light depending on their localization in the plant. They considered this complex expression pattern as an indication that the PHYA gene is subject to regulation by multiple signals, including environmental, developmental, and organ-specific signals. In line with this, we may assume the existence of similar properties of the POR gene.

In the context of the contrasting phyA $\mathrm{A}^{\prime}$ and phyA" functional properties of particular interest is the fact that their content in the plant is differentially regulated by red and far-red light. Constant illumination by R (Rc) of dark-grown seedlings (of pea) caused a gross decline in the total phyA content and a shift in the equilibrium towards the more light-stable phyA" due to a destruction primarily of the light-labile phyA' [39] whereas in the case of the constant far-red illumination of growing seedlings there was a considerable total phyA decline which was not followed by a violation in the equilibrium of its pools [87] (Figure 16). The nature of the effects of Rc and FRc on phyA and its pools was investigated using the point-mutated phyA-3D pea with the substitution A194V $[87,88]$. This mutation did not affect the spectroscopic and photochemical properties of phyA and the relative and total content of phyA' and phyA" in the dark-grown seedlings. At the same time, it brought about impaired photodestruction of phyA under Rc and dramatically enhanced responses under FRc (stem elongation, leaflet expansion, active and inactive protochlorophyllide accumulation, and phyA decline without violation of the $\mathrm{phyA}^{\prime} / \mathrm{phyA}^{\prime \prime}$ equilibrium). These observations higher activity and stability of phyA in the mutant and its more pronounced decline under FRc suggest the autodownregulation of phyA biosynthesis under FRc in contrast to its destruction under Rc. This notion is 


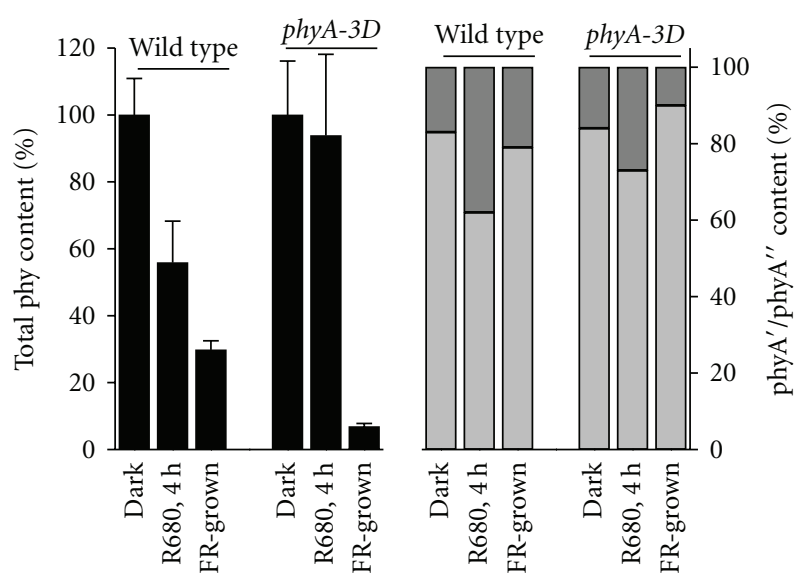

Figure 16: Two modes of light-induced phyA decline-with and without changes in the phyA'/phyA" equilibrium. Epicotyls of wild type pea and its point mutated phy $A-3 D$ species with alanine to valine substitution at position 194, A194V. Note that the decrease in the total phyA content in epicotyls of etiolated seedlings after saturating red illumination $\left(\lambda_{a}=680 \mathrm{~nm}, 4 \mathrm{~h}\right)$ is followed by a shift in the $\mathrm{phyA}^{\prime} / \mathrm{phyA}^{\prime \prime}$ equilibrium towards the less light-labile phy $\mathrm{A}^{\prime \prime}$ form whereas even much more pronounced decline of $\left[\mathrm{P}_{\text {tot }}\right]$ in seedlings grown under far-red light $\left(\lambda_{a} \geq 720 \mathrm{~nm}, \mathrm{I}=0.1 \mathrm{~W} \mathrm{~m}^{-2}\right)$ is practically not accompanied by violation in the equilibrium. Note also a much lower effect of Rc and a much higher effect of FRc on the total phytochrome content in the case of the pea mutant suggesting that this mutation makes the photoreceptor less lightlabile and more physiologically active. (From $[87,88]$ ).

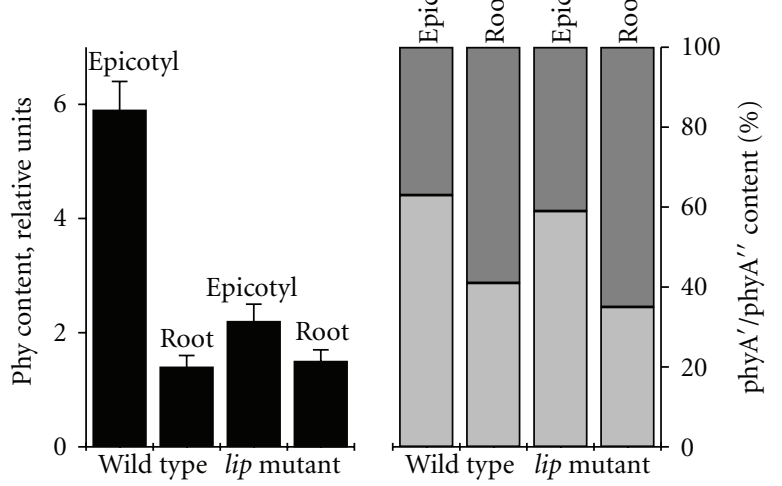

FIGURE 17: phyA decline without violation of the phyA'/phyA" equilibrium in epicotyls of the "de-etiolated" (lip) mutant of pea in the dark. The lip mutant (light-independent photomorphogenesis, lip) is deficient in negative regulators of photomorphogenesis resulting in "photomorphogenic" pattern of development in darkness. Note the absence of the effect of the lip mutation on phyA content in roots. (From [89], modified).

supported by the same mode of phyA decline (without the phyA'/phyA" ratio violation) observed even without FRc illumination in the epicotyls of the "de-etiolated" lip mutant of pea (Figure 17) [89]. phyA' thus seems to be dispensable under Rc and is active under FRc, while, on the contrary, phy $\mathrm{A}^{\prime \prime}$ is active under Rc and dispensable under
FRc. phyA ${ }^{\prime}$ is a prevailing and labile species in the darkgrown plants and is responsible for their de-etiolation while the minor and relatively light-stable phyA" may function under constant illumination throughout the whole plant life cycle. Proceeding from this and taking into account our observation (see above) that phyA" inhibits the action of phyA', we may hypothesize that the maintenance of the balance between the two phyA pools under different light conditions can be part of the mechanism of its fine-tuning.

\section{Conformers Within the PhyA' Type}

So far, we were talking about the products of different phytochrome genes with phyA and phyB as major ones and of the two phyA pools-different phyA posttranslationally modified states, phyA' and phyA" ${ }^{\prime \prime}$. We may thus consider two levels of organization of the phytochrome system. There seems to be, however, the third one-conformers within one molecular species of phytochrome. Within the phyA' type photochemically active at low temperatures, we have detected populations differing by the kinetic and activation parameters of the initial $\mathrm{Pr} \rightarrow$ lumi-R and reverse lumi- $\mathrm{R} \rightarrow \operatorname{Pr}$ photoreactions $[89,90]$. This was shown by the complex fluence-response curves for the phototransformations, which were deconvoluted into three components, whose proportion changed depending on the temperature of the sample (Figure 18). This suggests that the phyA' subpools have different activation barriers $E_{\mathrm{a}}$ in the excited state for the photoreactions (see scheme in Figure 6) and their concentrations at different temperatures depend on activation barriers in the ground state for conversion between them $[2,90]$. Functional implications of their existence remain unclear. However, it may explain literature data on complex kinetics of the Pr↔Pfr cycle of phototransformation with parallel routes (see discussion in [2]) and their investigations can help to deeper understand the intimate mechanisms of the phytochrome phototransformations.

\section{Conclusion}

Low-temperature fluorescence spectroscopy and photochemistry proved to be an efficient means of phytochrome assay in vivo. The photoreceptor was characterized by a number of physicochemical parameters which were variable depending on plant species and tissues, its developmental state, and physiological conditions. This strongly implied its heterogeneity which was found with the use of phytochrome mutants and overexpressors to be connected with phytochromes A and B, and, most importantly in the context of this discussion, with different native populations within phytochrome A-major and light-labile phyA and minor and relatively light-stable phy $\mathrm{A}^{\prime \prime}$. phyB was shown to be close by its photochemical and phenomenological properties to phyA". Both phyA species were products of one and the same gene differing by the character of plant-specific posttranslational modification. The site of the modification, possibly phosphorylation, is at the 6$\mathrm{kDa} \mathrm{N}$-terminal segment of the molecule as shown by 


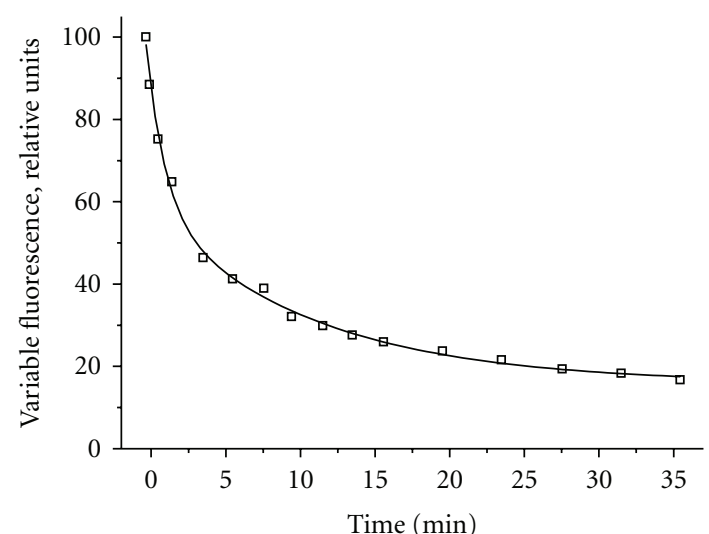

(a)

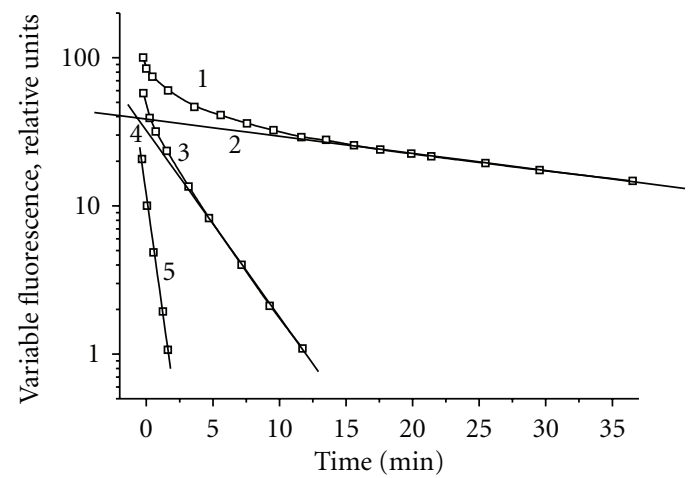

(c)

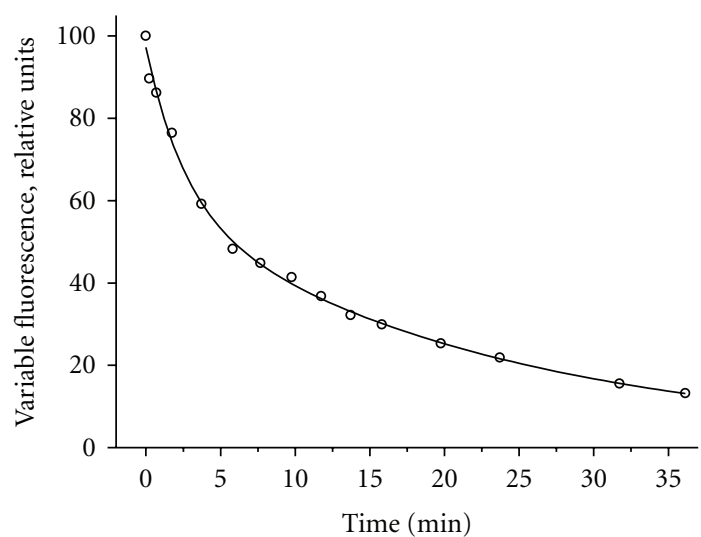

(b)

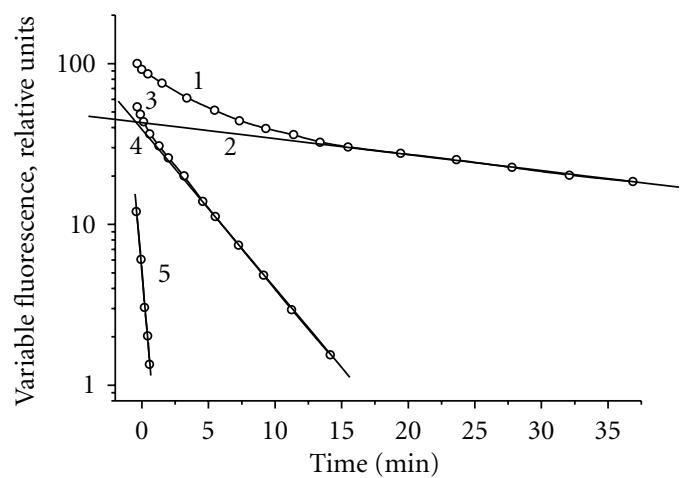

(d)

FIGURE 18: Low-temperature ( $85 \mathrm{~K}$ ) fluence-response curves for changes in phytochrome Pr concentration during its phototransformation into lumi-R (a) and back (b) at $85 \mathrm{~K}$ in etiolated (a) and preilluminated with saturating red light at $85 \mathrm{~K}$ (b) pea stems upon illumination with red and far-red light, respectively. The curves are obtained from the changes in Pr fluorescence $\left(\lambda_{e}=610 \mathrm{~nm}, \lambda_{m}=686 \mathrm{~nm}\right)$ as $f_{1}(t)=\mathrm{F}_{t}-\mathrm{F}_{1}$ in (a) and as $f_{2}(t)=\mathrm{F}_{2}-\mathrm{F}_{t}$ in (b). ( $\mathrm{F}_{1}$ and $\mathrm{F}_{2}$ are the Pr fluorescence intensity at photoequilibrium between Pr and lumi-R under saturating red $\left(\lambda_{r}=667 \mathrm{~nm}\right)$ and far-red $\left(\lambda_{f r}=696 \mathrm{~nm}\right)$ light, respectively; $\mathrm{F}_{t}$ is the fluorescence intensity of Pr at various times of illumination with red $\left(\lambda_{r}=667 \mathrm{~nm}\right)$ or far-red $\left(\lambda_{f r}=696 \mathrm{~nm}\right)$ light. Parts (c) and (d) present deconvolution of the experimental curves in (a) and (b), respectively, in semilogarithmic coordinates. (From [89]).

experiments with truncated pigment species. Composite kinetics of the phyA' photoreaction at low temperatures revealed yet another level of phyA complexity-existence of different conformers within the phyA' molecular type. Correlative experiments on phyA' and phyA" content in phyA overexpressors and modifications of their phenotype suggest that phyA' is functional in de-etiolation under FR (FR-HIR and VLFR modes) whereas phyA" is involved in reactions under R (LFR mode). Besides phyA" suppresses phyA' and regulation of the ratio between them can be an important element of the mechanism of phyA action. Thus, polymorphism of phyA may explain, at least partially, the complexity and specificity of its photophysiology.

\section{Acknowledgments}

The author expresses deep gratitude to his coworkers and coauthors of his publications. This work was supported in part by the Russian Foundation for the Fundamental Investigations, Grant no. 08-04-01453 to V. A. Sineshchekov

\section{References}

[1] W. L. Butler, K. H. Norris, H. W. Siegelman, and S. B. Hendricks, "Detection, assay, and preliminary purification of the pigment controlling photoresponsive development of plants," Proceedings of the National Academy of Sciences of USA, vol. 45, pp. 1703-1708, 1959.

[2] V. A. Sineshchekov, "Photobiophysics and photobiochemistry of the heterogeneous phytochrome system," Biochimica et Biophysica Acta, vol. 1228, no. 2-3, pp. 125-164, 1995.

[3] S.-L. Tu and J. C. Lagarias, "The phytochromes," in Handbook of Photosensory Receptors, W. R. Briggs and J. L. Spudich, Eds., pp. 122-139, WILEY-VCH Verlag Gmbh and Co. KgaA, Weinheim, Germany, 2005.

[4] N. C. Rockwell, Y.-S. Su, and J. C. Lagarias, "Phytochrome structure and signaling mechanisms," Annual Review of Plant Biology, vol. 57, pp. 837-858, 2006.

[5] E. Schäfer and F. Nagy, Eds., Photomorphogenesis in Plants and Bacteria, Springer, Dordrecht, The Netherlands, 3rd edition, 2006.

[6] "Photomorphogenesis," in Plant, Cell \& Environment, $\mathrm{H}$. Smith, Ed., vol. 20, pp. 657-844, 1997. 
[7] H. Wang and X. W. Deng, "Dissecting the phytochrome Adependent signaling network in higher plants," Trends in Plant Science, vol. 8, no. 4, pp. 172-178, 2003.

[8] W. R. Briggs and J. L. Spudich, Eds., Handbook of Photosensory Receptors, WILEY-VCH Verlag Gmbh and Co. KgaA, Weinheim, Germany, 2005.

[9] M. Wada, K. Shimazaki, and M. Iino, Eds., Light Sensing in Plants, Springer, Tokyo, Japan, 2005.

[10] J. Brockman and E. Schäfer, "Analysis of Pfr destruction in Amarantus caudatus L.- - evidence for two pools of phytochrome," Photochemistry and Photobiology, vol. 35, no. 4, pp. 555-558, 1982.

[11] J. G. Tokuhisa, S. M. Daniels, and P. H. Quail, "Phytochrome in green tissue: spectral and immunochemical evidence for two distinct molecular species of phytochrome in light-grown Avena sativa L," Planta, vol. 164, no. 3, pp. 321-332, 1985.

[12] L. H. Pratt, "Distribution and localization of phytochrome within the plant," in Photomorphogenesis in Plants, R. E. Kendrick and G. H. M. Kronenberg, Eds., pp. 163-186, Kluver Academic Publishers, London, UK, 2nd edition, 1994.

[13] V. A. Sineshchekov and A. V. Sineshchekov, "Fluorescence and absorption investigations of phytochrome in the cells of etiolated seedlings," Plant Physiology, vol. 34, pp. 730-741, 1987 (Russian).

[14] V. A. Sineshchekov and A. V. Sineshchekov, "Fluorescence of phytochrome in the cells of dark-grown plants and its connection with the phototransformations of the pigment," Photochemistry and Photobiology, vol. 49, pp. 325-330, 1989.

[15] R. A. Sharrock and P. H. Quail, "Novel phytochrome sequences in Arabidopsis thaliana: structure, evolution, and differential expression of a plant regulatory photoreceptor family," Genes \& Development, vol. 3, no. 11, pp. 1745-1757, 1989.

[16] M. Furuya, "Phytochromes: their molecular species, gene families, and functions," Annual Review of Plant Physiology and Plant Molecular Biology, vol. 44, no. 1, pp. 617-645, 1993.

[17] B. M. Parks and E. P. Spalding, "Sequential and coordinated action of phytochromes A and B during Arabidopsis stem growth revealed by kinetic analysis," Proceedings of the National Academy of Sciences of the United States of America, vol. 96, no. 24, pp. 14142-14146, 1999.

[18] C. Long and M. Iino, "Light-dependent osmoregulation in pea stem protoplasts. Photoreceptors, tissue specificity, ion relationships, and physiological implications," Plant Physiology, vol. 125, no. 4, pp. 1854-1869, 2001.

[19] M. Takano, H. Kanegae, T. Shinomura, A. Miyao, H. Hirochika, and M. Furuya, "Isolation and characterization of rice phytochrome A mutants," Plant Cell, vol. 13, no. 3, pp. 521-534, 2001.

[20] J. Z. Kiss, J. L. Mullen, M. J. Correll, and R. P. Hangarter, "Phytochromes A and B mediate red-light-induced positive phototropism in roots," Plant Physiology, vol. 131, no. 3, pp. 1411-1417, 2003.

[21] M. Takano, N. Inagaki, X. Xie et al., "Distinct and cooperative functions of phytochromes $\mathrm{A}, \mathrm{B}$, and $\mathrm{C}$ in the control of deetiolation and flowering in rice," Plant Cell, vol. 17, no. 12, pp. 3311-3325, 2005.

[22] V. Sineshchekov, A. Loskovich, N. Inagaki, and M. Takano, "Two native pools of phytochrome A in monocots: evidence from fluorescence investigations of phytochrome mutants of rice," Photochemistry and Photobiology, vol. 82, no. 4, pp. 1116-1122, 2006.
[23] J. M. Tepperman, Y.-S. Hwang, and P. H. Quail, "phyA dominates in transduction of red-light signals to rapidly responding genes at the initiation of Arabidopsis seedling deetiolation," Plant Journal, vol. 48, no. 5, pp. 728-742, 2006.

[24] K. A. Franklin, T. Allen, and G. C. Whitelam, "Phytochrome A is an irradiance-dependent red light sensor," Plant Journal, vol. 50, no. 1, pp. 108-117, 2007.

[25] R. A. Sharrock and T. Clack, "Patterns of expression and normalized levels of the five Arabidopsis phytochromes," Plant Physiology, vol. 130, no. 1, pp. 442-456, 2002.

[26] V. A. Sineshchekov, "Phytochrome A: functional diversity and polymorphism," Photochemical and Photobiological Sciences, vol. 3, no. 6, pp. 596-607, 2004.

[27] V. Sineshchekov, "Phytochrome A: two native pools in the cell with diverse spectroscopic, photochemical and functional properties," in Photochemistry Research Progress, A. Sánchez and S. J. Gutierrez, Eds., pp. 37-100, Nova Science, New York, NY, USA, 2008.

[28] V. A. Sineshchekov and A. V. Sineshchekov, "Method of determination of the state of phytochrome in the plant cell," Patent No.1450788, USSR Committee of Inventions and Discoveries, 1986 (Russian).

[29] V. A. Sineshchekov and A. V. Sineshchekov, "Fluorescence of phytochrome in the cell," Doklady Akademii Nauk SSSR, vol. 292, pp. 477-481, 1987 (Russian).

[30] V. A. Sineshchekov and A. V. Sineshchekov, "Fluorescence of phytochrome in the cells of etiolated pea seedlings," Biofizika, vol. 32, pp. 110-115, 1987 (Russian).

[31] V. A. Sineshchekov and A. V. Sineshchekov, "Procedure for combined fluorescence-absorption investigation of phytochrome in plant tissues," Plant Physiology, vol. 34, pp. 832836, 1987 (Russian).

[32] V. A. Sineshchekov and A. V. Sineshchekov, "Fluorescence and photoconversions of the native states of the red form of phytochrome in the cells of etiolated pea seedlings," Biofizika, vol. 34, no. 4, pp. 658-665, 1989 (Russian).

[33] V. A. Sineshchekov and W. Rüdiger, "Fluorescence spectroscopy of stable and labile phytochrome in stems and roots of etiolated cress seedlings," Photochemistry and Photobiology, vol. 56, no. 5, pp. 735-742, 1992.

[34] V. Sineshchekov, "Two spectroscopically and photochemically distinguishable phytochromes in etiolated seedlings of monocots and dicots," Photochemistry and Photobiology, vol. 59, no. 1, pp. 77-85, 1994.

[35] V. A. Sineshchekov and A. V. Sineshchekov, "Different photoactive states of the red phytochrome form in the cells of etiolated pea and oat seedlings," Journal of Photochemistry and Photobiology B, vol. 5, no. 2, pp. 197-217, 1990.

[36] V. A. Sineshchekov, V. N. Lapko, A. V. Sineshchekov, G. V. Kozhukh, and A. V. Udal'tsov, "Fluorescence studies of phytochrome in the cells of etiolated oat seedlings and $124-\mathrm{kDa}$ phytochrome isolated from them," Journal of Photochemistry and Photobiology B, vol. 5, no. 2, pp. 219-229, 1990.

[37] M. E. Lippitsch, G. Hermann, H. Brunner, E. Muller, and F. R. Aussenegg, "Picosecond events in the phototransformation of phytochrome-a time-resolved absorption study," Journal of Photochemistry and Photobiology B, vol. 18, no. 1, pp. 17-25, 1993.

[38] V. A. Sineshchekov, O. B. Ogorodnikova, P. F. Devlin, and G. C. Whitelam, "Fluorescence spectroscopy and photochemistry of phytochromes A and B in wild-type, mutant and transgenic strains of Arabidopsis thaliana," Journal of Photochemistry and Photobiology B, vol. 42, no. 2, pp. 133-142, 1998. 
[39] V. A. Sineshchekov, O. B. Ogorodnikova, and J. L. Weller, "Fluorescence and photochemical properties of phytochromes A and B in etiolated pea seedlings," Journal of Photochemistry and Photobiology B, vol. 49, no. 2-3, pp. 204-211, 1999.

[40] V. Sineshchekov, O. Ogorodnikova, A. Thiele, and C. Gatz, "Fluorescence and photochemical characterization of phytochromes A and B in transgenic potato expressing Arabidopsis phytochrome B," Journal of Photochemistry and Photobiology $B$, vol. 59, no. 1-3, pp. 139-146, 2000.

[41] V. A. Sineshchekov, "Evidence for the existence of two phytochrome A populations," Journal of Photochemistry and Photobiology B, vol. 28, no. 1, pp. 53-55, 1995.

[42] V. A. Sineshchekov, A. G. Heyer, and C. Gatz, "Phytochrome states in transgenic potato plants with altered phytochrome A levels," Journal of Photochemistry and Photobiology B, vol. 34, no. 2-3, pp. 137-142, 1996.

[43] V. A. Sineshchekov, R. C. Clough, E. T. Jordan-Beebe, and R. D. Vierstra, "Fluorescence analysis of oat phyA deletion mutants expressed in tobacco suggests that the N-terminal domain determines the photochemical and spectroscopic distinctions between phy $\mathrm{A}^{\prime}$ and phy $\mathrm{A}^{\prime \prime}$, , Photochemistry and Photobiology, vol. 69, no. 6, pp. 728-732, 1999.

[44] V. Sineshchekov, L. Hennig, T. Lamparter, J. Hughes, W. Gärtner, and E. Schäfer, "Recombinant phytochrome A in yeast differs by its spectroscopic and photochemical properties from the major phyA and is close to the minor phyA": evidence for posttranslational modification of the pigment in plants," Photochemistry and Photobiology, vol. 73, no. 6, pp. 692-696, 2001.

[45] V. Sineshchekov and M. Zeidler, unpublished results.

[46] V. Sineshchekov, A. Sudnitsin, E. Adam, F. Nagy, and E. Schäfer, unpublished results.

[47] K.-C. Yeh and J. C. Lagarias, "Eukaryotic phytochromes: light-regulated serine/threonine protein kinases with histidine kinase ancestry," Proceedings of the National Academy of Sciences of the United States of America, vol. 95, no. 23, pp. 13976-13981, 1998.

[48] C. Fankhauser, "Phytochromes as light-modulated protein kinases," Seminars in Cell and Developmental Biology, vol. 11, no. 6, pp. 467-473, 2000.

[49] J.-I. Kim, J.-E. Park, X. Zarate, and P.-S. Song, "Phytochrome phosphorylation in plant light signaling," Photochemical and Photobiological Sciences, vol. 4, no. 9, pp. 681-687, 2005.

[50] J. S. Ryu, J.-I. Kim, T. Kunkel et al., "Phytochrome-specific type 5 phosphatase controls light signal flux by enhancing phytochrome stability and affinity for a signal transducer," Cell, vol. 120, no. 3, pp. 395-406, 2005.

[51] Y.-J. Han, H.-S. Kim, Y.-M. Kim et al., "Functional characterization of phytochrome autophosphorylation in plant light signaling," Plant and Cell Physiology, vol. 51, no. 4, pp. 596609, 2010.

[52] P.-S. Song, personal communication.

[53] C. Fankhauser, K.-C. Yeh, J. C. Lagarias, H. Zhang, T. D. Elich, and J. Chory, "PKS1, a substrate phosphorylated by phytochrome that modulates light signaling in Arabidopsis," Science, vol. 284, no. 5419, pp. 1539-1541, 1999.

[54] P. Lariguet, H. E. Boccalandro, J. M. Alonso et al., "A growth regulatory loop that provides homeostasis to phytochrome A signaling," Plant Cell, vol. 15, no. 12, pp. 2966-2978, 2003.

[55] V. Sineshchekov and C. Fankhauser, "PKS1 and PKS2 affect the phyA state in etiolated Arabidopsis seedlings," Photochemical and Photobiological Sciences, vol. 3, no. 6, pp. 608-611, 2004.
[56] A. R. Cashmore, J. A. Jarillo, Y.-J. Wu, and D. Liu, "Cryptochromes: blue light receptors for plants and animals," Science, vol. 284, no. 5415, pp. 760-765, 1999.

[57] M. Ahmad, J. A. Jarillo, O. Smirnova, and A. R. Cashmore, "The CRY1 blue light photoreceptor of Arabidopsis interacts with phytochrome a in vitro," Molecular Cell, vol. 1, no. 7, pp. 939-948, 1998.

[58] M. Furuya and P.-S. Song, "Assembly and properties of holophytochrome," in Photomorphogenesis in Plants, R. E. Kendrick and G. H. M. Kronenberg, Eds., pp. 105-140, Kluwer Academic Publishers, London, UK, 2nd edition, 1994.

[59] T. Lamparter, P. Lutterbuse, H. A. W. Schneider-Poetsch, and R. Hertel, "A study of membrane-associated phytochrome: hydrophobicity test and native size determination," Photochemistry and Photobiology, vol. 56, pp. 697-707, 1992.

[60] M. J. Terry, J. L. Hall, and B. Thomas, "The association of type I phytochrome with wheat leaf plasma membranes," Journal of Plant Physiology, vol. 140, no. 6, pp. 691-698, 1992.

[61] P. H. Quail, "Phytochrome-interacting factors," Seminars in Cell and Developmental Biology, vol. 11, no. 6, pp. 457-466, 2000.

[62] V. Sineshchekov, T. Lamparter, and E. Hartmann, "Evidence for the existence of membrane-associated phytochrome in the cell," Photochemistry and Photobiology, vol. 60, no. 5, pp. 516520, 1994

[63] V. A. Sineshchekov, "Extreme dehydration of plant tissues irreversibly converts the major and variable phyA' into the minor and conserved phyA'," Journal of Photochemistry and Photobiology B, vol. 85, no. 2, pp. 85-91, 2006.

[64] M. Furuya, "History and insights," in Light Sensing in Plants, M. Wada, K. Shimazaki, and M. Iino, Eds., pp. 3-18, Springer, Tokyo, Japan, 2005.

[65] F. Nagy, S. Kircher, and E. Schäfer, "Intracellular trafficking of photoreceptors during light-induced signal transduction in plants," Journal of Cell Science, vol. 114, no. 3, pp. 475-480, 2001.

[66] A. Sudnitsin, E. Adam, F. Nagy, E. Schäfer, and V. Sineshchekov, "phyA-GFP is spectroscopically and photochemically close to phyA and comprises both phy' and phyA," in Proceedings of the Plant Photobiology Meeting, Marburg, Germany, 2003, Abstract P9.

[67] V. Sineshchekov, A. Sudnitsin, E. Adam, F. Nagy, and E. Schäfer, unpublished results.

[68] J. J. Casal, S. J. Davis, D. Kirchenbauer et al., "The serine-rich N-terminal domain of oat phytochrome A helps regulate light responses and subnuclear localization of the photoreceptor," Plant Physiology, vol. 129, no. 3, pp. 1127-1137, 2002.

[69] V. Sineshchekov, L. Koppel, L. Shlumukov et al., "Fluorescence and photochemical properties of phytochromes in wildtype wheat and a transgenic line overexpressing an oat phytochrome A (PHYA) gene: functional implications," Plant, Cell and Environment, vol. 24, no. 12, pp. 1289-1297, 2001.

[70] V. Sineshchekov, O. Belyaeva, and A. Sudnitsin, "Upregulation by phytochrome A of the active protochlorophyllide, Pchlide ${ }^{655}$, biosynthesis in dicots under far-red light," Journal of Photochemistry and Photobiology B, vol. 74, no. 1, pp. 47-54, 2004.

[71] V. Sineshchekov, unpublished results.

[72] J. J. Casal, "Phytochromes, cryptochromes, phototropin: photoreceptor interactions in plants," Photochemistry and Photobiology, vol. 71, no. 1, pp. 1-11, 2000. 
[73] J. W. Reed, P. Nagpal, D. S. Poole, M. Furuya, and J. Chory, "Mutations in the gene for the red/far-red light receptor phytochrome B alter cell elongation and physiological responses throughout Arabidopsis development," Plant Cell, vol. 5, no. 2, pp. 147-157, 1993.

[74] P. F. Devlin and S. A. Kay, "Cryptochromes are required for phytochrome signaling to the circadian clock but not for rhythmicity," Plant Cell, vol. 12, no. 12, pp. 2499-2509, 2000.

[75] S. A. Trupkin, D. Debrieux, A. Hiltbrunner, C. Fankhauser, and J. J. Casal, "The serine-rich N-terminal region of Arabidopsis phytochrome A is required for protein stability," Plant Molecular Biology, vol. 63, no. 5, pp. 669-678, 2007.

[76] M. J. Yanovsky, J. P. Luppi, D. Kirchbauer et al., "Missense mutation in the PAS2 domain of phytochrome A impairs subnuclear localization and a subset of responses," Plant Cell, vol. 14, no. 7, pp. 1591-1603, 2002.

[77] J. L. Mateos, J. P. Luppi, O. B. Ogorodnikova et al., "Functional and biochemical analysis of the N-terminal domain of phytochrome A," Journal of Biological Chemistry, vol. 281, no. 45, pp. 34421-34429, 2006.

[78] V. Sineshchekov, O. Ogorodnikova, and J. Casal, unpublished results.

[79] K. Apel, H. J. Santel, T. E. Redlinger, and H. Falk, "The protochlorophyllide holochrome of barley. Isolation and characterization of the NADPH:protochlorophyllide oxidoreductase," European Journal of Biochemistry, vol. 111, no. 1, pp. 251-258, 1980.

[80] K. Apel, "The protochlorophyllide holochrome of barley (Hordeum vulgare L.). Phytochrome-induced decrease of translatable mRNA coding for the NADPH:protochlorophyllide oxidoreductase," European Journal of Biochemistry, vol. 120, no. 1, pp. 89-93, 1981.

[81] S. A. Barnes, N. K. Nishizawa, R. B. Quaggio, G. C. Whitelam, and N.-H. Chua, "Far-red light blocks greening of Arabidopsis seedlings via a phytochrome A-mediated change in plastid development," Plant Cell, vol. 8, no. 4, pp. 601-615, 1996.

[82] M. J. Yanovsky, C. C. Whitelam, and J. J. Casal, "fhy3-1 retains inductive responses of phytochrome A," Plant Physiology, vol. 123, no. 1, pp. 235-242, 2000.

[83] S. Runge, U. Sperling, G. Frick, K. Apel, and G. A. Armstrong, "Distinct roles for light-dependent NADPH:protochlorophyllide oxidoreductases (POR) A and B during greening in higher plants," Plant Journal, vol. 9, no. 4, pp. 513-523, 1996.

[84] V. Sineschekov, A. V. Loskovich, M. Riemann, and P. Nick, "The jasmonate-free rice mutant hebiba is affected in the response of $\mathrm{phyA}^{\prime} / \mathrm{phyA}^{\prime \prime}$ pools and protochlorophyllide biosynthesis to far-red light," Photochemical and Photobiological Sciences, vol. 3, no. 11-12, pp. 1058-1062, 2004.

[85] R. Schendel, D. Dörnemann, W. Rüdiger, and V. Sineshchekov, "Comparative investigations of the effect of 5-aminolevulinate feeding on phytochrome and protochlorophyll(ide) content in dark-grown seedlings of barley, cucumber and cress," Journal of Photochemistry and Photobiology B, vol. 36, no. 3, pp. 245253, 1996.

[86] F. R. Cantón and P. H. Quail, "Both phyA and phyB mediate light-imposed repression of phyA gene expression in Arabidopsis," Plant Physiology, vol. 121, no. 4, pp. 1207-1215, 1999.

[87] V. A. Sineshchekov and J. L. Weller, "Two modes of the lightinduced phytochrome A decline-with and without changes in the relative content of its native pools ( phyA $^{\prime}$ and phyA $^{\prime \prime}$ ): evidence from in situ fluorescence investigations of wild-type and mutant phyA-3D pea," Journal of Photochemistry and Photobiology A, vol. 75, pp. 127-135, 2004.
[88] J. L. Weller, S. L. Batge, J. J. Smith et al., “A dominant mutation in the pea PHYA gene confers enhanced responses to light and impairs the light-dependent degradation of phytochrome A," Plant Physiology, vol. 135, no. 4, pp. 2186-2195, 2004.

[89] V. A. Sineshchekov, S. Frances, and M. J. White, "Fluorescence and photochemical characterization of phytochrome in deetiolated pea mutant lip," Journal of Photochemistry and Photobiology B, vol. 28, no. 1, pp. 47-51, 1995.

[90] V. A. Sineshchekov and V. V. Akhobadze, "Phytochrome states in etiolated pea seedlings: fluorescence and primary photoreactions at low temperatures," Photochemistry and Photobiology, vol. 56, pp. 743-749, 1992. 

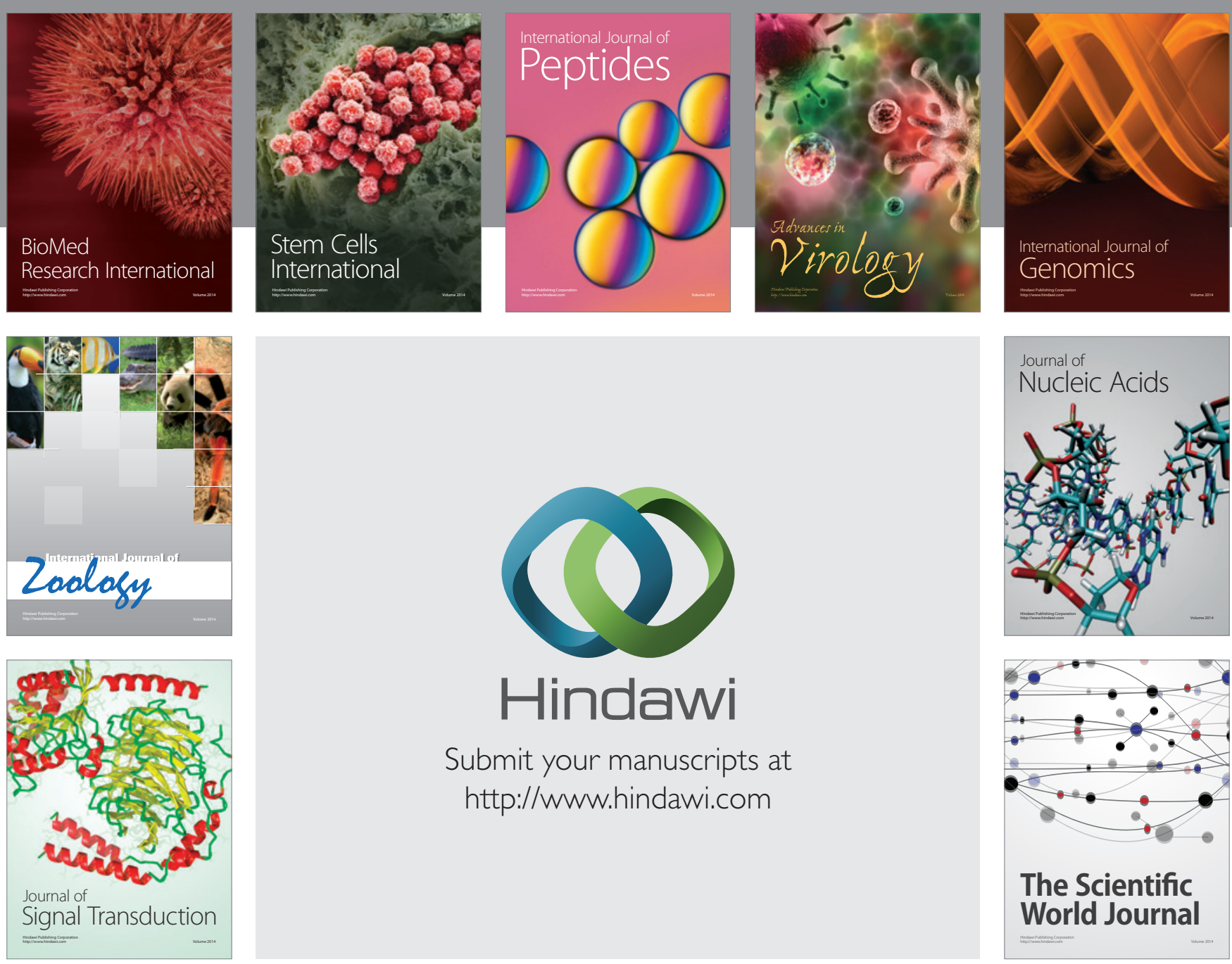

Submit your manuscripts at

http://www.hindawi.com
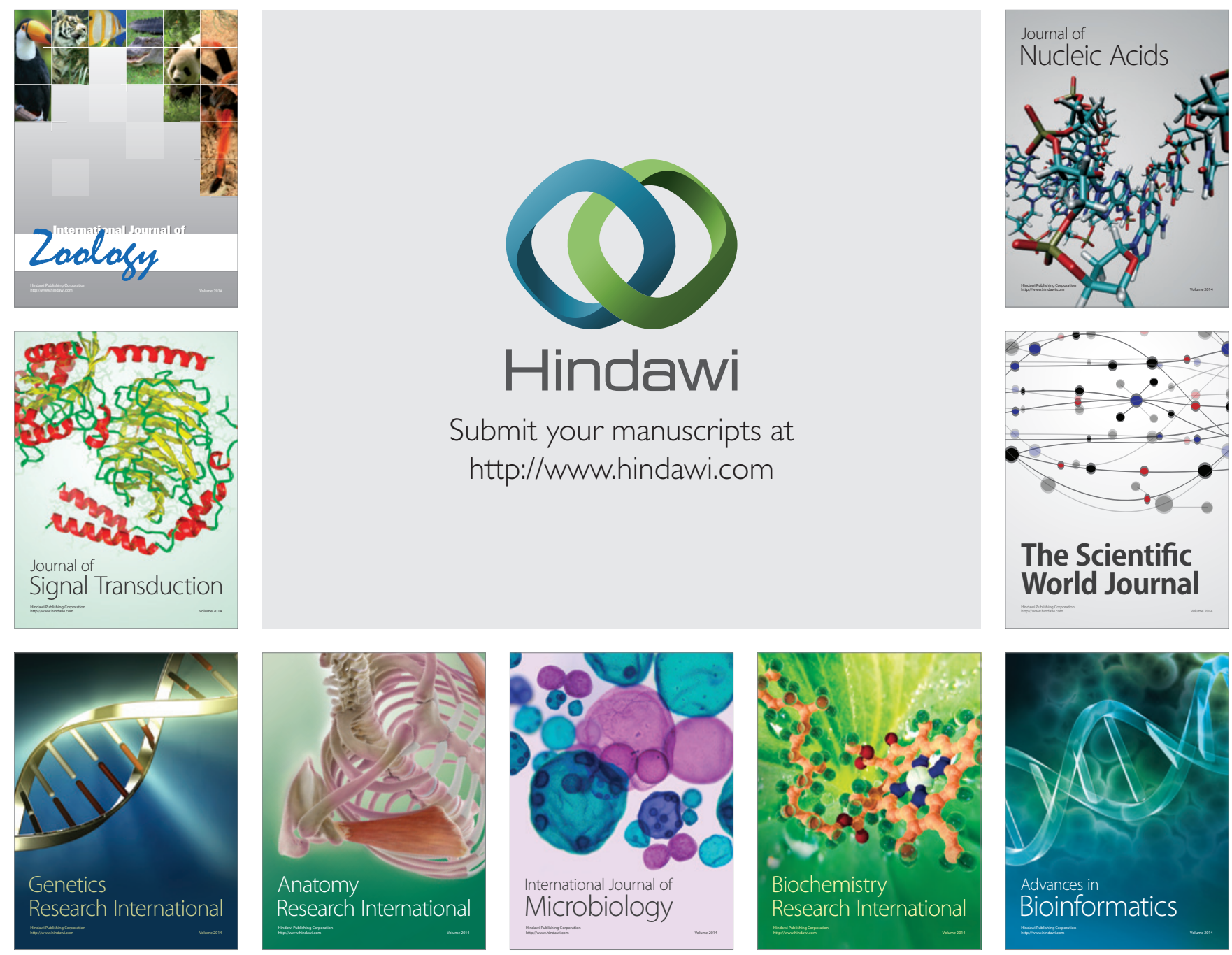

The Scientific World Journal
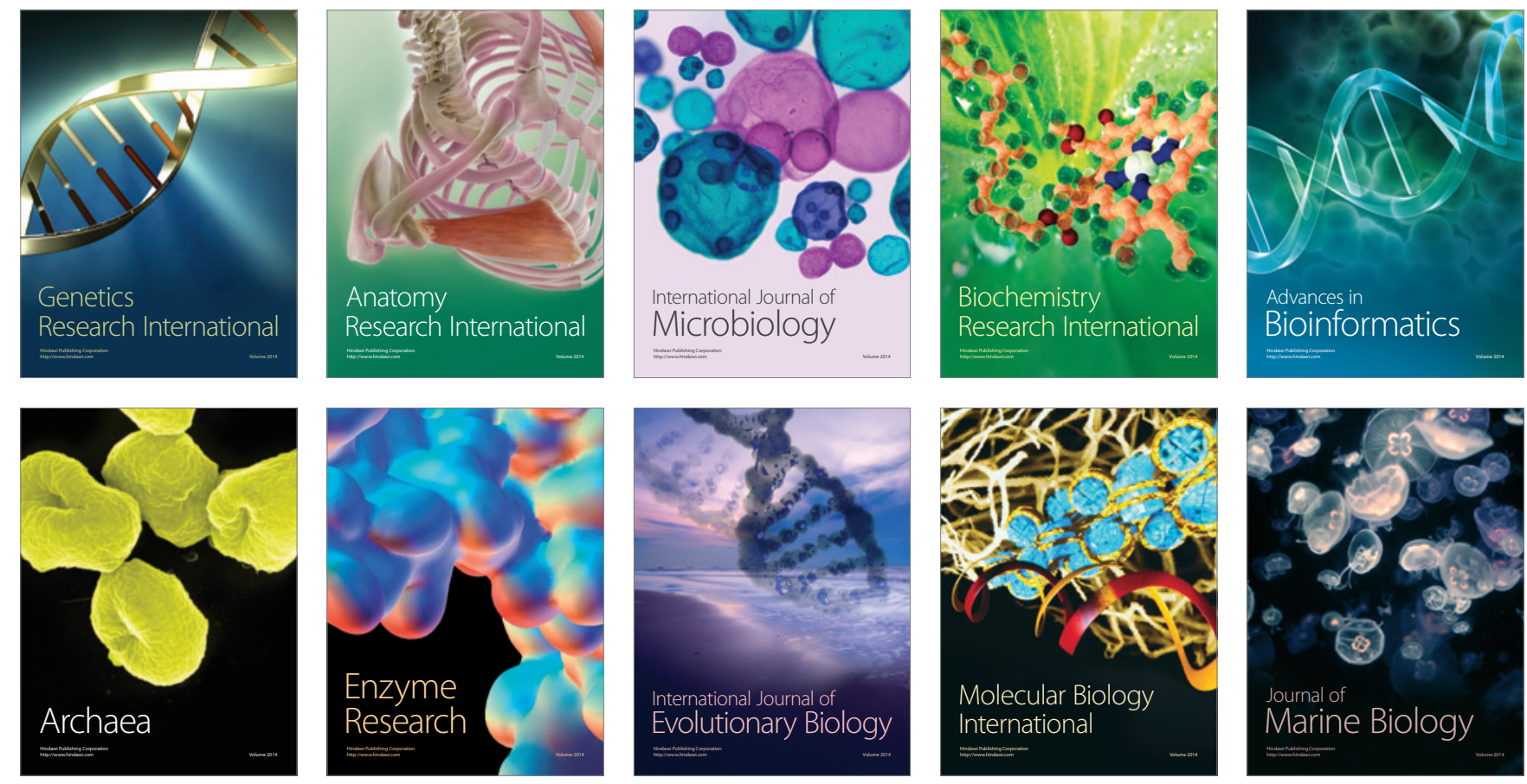